\title{
Mezzi di trasporto del campione biologico: contenitori e terreni
}

\author{
Graziella Marin*, Graziella Gava** \\ * Laboratorio di Patologia Clinica,Ospedale Santa Maria del Carmine, Rovereto (TN) \\ ** Struttura Operativa Semplice di Immunologia clinica e Virologia , Dipartimento di Medicina di Laboratorio, Azienda \\ Ospedaliera Santa Maria degli Angeli, Pordenone
}

\section{INTRODUZIONE}

La raccolta, il trasporto e la conservazione dei campioni sono la base fondamentale per produrre risultati attendibili. Presupposto per una sicura qualità diagnostica è che il laboratorio di microbiologia fornisca agli utenti, siano essi reparti di degenza, medici o pazienti, linee guida specifiche per una adeguata raccolta ed un corretto trasporto dei campioni biologici. Una fase preanalitica non rispondente ai requisiti previsti porta ad un sicuro insuccesso nell'isolamento dei microrganismi responsabili della patologia del paziente, a causa della possibilità di sviluppo di contaminanti che possono indurre alla somministrazione di terapie antibiotiche inutili. E' proprio questo il motivo per il quale in questi ultimi anni sono state predisposte diverse linee guida generali e manuali che trattano questo argomento e danno indicazioni ben precise, con l'obiettivo di prolungare nel tempo la vitalità dei microrganismi e per accertare eventuali effetti tossici dei materiali utilizzati (2). In questi ultimi anni la necessità di disporre di sistemi di trasporto è aumentata ulteriormente a causa di un maggior ricorso alle attività ambulatoriali in seguito alla riduzione del numero dei giorni di degenza ed alla progressiva centralizzazione dei laboratori dovuta a nuovi assetti organizzativi.

Attualmente sono disponibili, per la raccolta ed il trasporto dei campioni clinici sistemi completi pronti all'uso e sterili. Ma quali garanzie di qualità danno?

Per rispondere a questa domanda è necessario approfondire il tema del controllo di qualità dei sistemi di trasporto(9). E le novità e l'interesse in questo campo non mancano come si può dedurre dai numerosi lavori di valutazione pubblicati nell'ultimo decennio. E' aumentata soprattutto l'attenzione per uno dei fattori esterni che condizionano tutto il sistema: la temperatura di conservazione dei microrganismi. L'anno 2002 può considerarsi a tutti gli effetti una data storica a tal proposito . L'NCCLS ha pubblicato infatti, a dicembre 2002, il documento M40-P: "Quality Control Standards of Microbiological Transport System; Proposed Standard", che comprende gli standard per valutare la performance dei dispositivi di trasporto e stabilisce i criteri di accettabilità. In particolare riconosce che la temperatura ha un significativo effetto sulla conservazione dei microrganismi nei vari dispositivi di trasporto: la migliore temperatura di conservazione risulta essere $4^{\circ} \mathrm{C}$, per cui i produttori di dispositivi vengono invitati ad eseguire controlli di qualità sia a temperatura ambiente che a $4^{\circ}-8^{\circ} \mathrm{C}$ segnalandoli nel foglietto illustrativo del prodotto. Il primo semestre 2003 vede già alcuni lavori di comparazione, secondo le nuove disposizioni e questi confermano la superiorità di questa temperatura nel garantire la sopravvivenza per tempi prolungati della maggior parte degli microrganismi difficili.

Nell'analisi dettagliata di questi aspetti della fase preanalitica, legati alla tipologia dei sistemi di trasporto, si farà riferimento, in particolare, al Clinical Microbiology Procedures Handbook 1992 - Henry D. Isenberg Vol 1 Specimen Collection and Transport (1)

\section{PRINCIPI GENERALI}

Il campione per esame microbiologico va trasportato nel più breve tempo possibile al laboratorio:

- Per assicurare la sopravvivenza e l'isolamento dei microrganismi patogeni e per prevenire una crescita veloce dei batteri più resistenti.

- Per abbreviare la durata del contatto dei campioni con alcuni anestetici locali usati nelle procedure di raccolta che possono avere attività antibatterica

- Per provvedere a diagnosi più accurata dei processi delle malattie infettive.

In alternativa ad una pronta consegna si deve operare come segue:

- refrigerare i campioni a $2-8^{\circ} \mathrm{C}$ tranne che nel caso di:

1. sangue in brodocoltura, che va incubato a 35$37^{\circ} \mathrm{C}$ o ISOLATOR che va mantenuto a temperatura ambiente

2. campioni che possono contenere microrganismi sensibili alle temperature come le Neisserie spp. che devono essere lasciati a temperatura ambiente

3. campioni per la ricerca di batteri anaerobi; (utilizzare sempre un sistema di trasporto specifico)

4. campioni di feci per l'esame colturale: usare un terreno di trasporto (Cary Blair medium o Buffered glycerol Saline)

5. campioni di feci per l'esame parassitologico : 
mescolare il campione con conservante

6. campioni di CSF che devono essere mantenuti a temperatura ambiente a meno che non debba essere fatta una coltura per virus

- usare sistemi di trasporto:

1. per anaerobi: per assicurare la vitalità degli organismi anaerobi; alcuni esempi sono descritti nella tabella 1
2. per aerobi: alcuni metodi di trasporto sono descritti nella tabella 2. Benché sia possibile utilizzare tamponi sterili per la raccolta e trasporto dei campioni, è necessario valutare a priori quale sistema adottare a seconda del test richiesto.

3. contenitori di trasporto specifici per campioni biologici; descritti nella tabella 3

Tabella I. Sistemi di trasporto per anaerobi

\begin{tabular}{|c|c|}
\hline SISTEMI E FORNITORE & DESCRIZIONE \\
\hline $\begin{array}{l}\text { Anaswab system } \\
\text { Scott laboratories, Inc. } \\
\text { Fiskeville, R.I. }\end{array}$ & $\begin{array}{l}\text { Sistema a } 2 \text { provette, entrambe in anaerobiosi. Una provetta contiene il tampone } \\
\text { collegato ad uno stopper di gomma. Prelevato il campione con il tampone, questo } \\
\text { viene inserito nella seconda provetta e chiuso ermeticamente con il tappo di gomma. }\end{array}$ \\
\hline $\begin{array}{l}\text { Port-a-Cult Vial or Port-a-Cult swab } \\
\text { BBL Microbiology Systems } \\
\text { Cockeysville, Md. }\end{array}$ & $\begin{array}{l}\text { La provetta viene usata per il trasporto dei tamponi. La fiala sigillata per il trasporto di } \\
\text { campioni liquidi. Entrambi contengono un terreno di trasporto semisolido con agenti } \\
\text { deossidanti ed indicatore di ossidoriduzione. Qualsiasi variazione del colore porpora } \\
\text { del terreno indica esposizione all'aria. }\end{array}$ \\
\hline $\begin{array}{l}\text { Bio-Bag Environmental System } \\
\text { BBL Microbiology Systems } \\
\text { Cockeysville, Md. }\end{array}$ & $\begin{array}{l}\text { Il campione raccolto con qualsiasi tipo di tampone o provetta desiderato viene inserito } \\
\text { in un contenitore dove sono predisposte delle ampolle contenenti: indicatore, } \\
\text { catalizzatore e generatore di idrogeno - CO2. Sigillato il contenitore è necessario } \\
\text { rompere ciascuna ampolla per la produzione delle condizioni di anaerobiosi. }\end{array}$ \\
\hline $\begin{array}{l}\text { Syringe or needle aspirates } \\
\text { (Agoaspirati) }\end{array}$ & $\begin{array}{l}\text { Eliminare l'aria in eccesso dalla siringa, aspirare il materiale, sigillare la siringa senza ago } \\
\text { con apposito tappo o inserire l'ago in un tappo di gomma. Se si sono prelevati } 2 \text { o più } \\
\mathrm{ml} \text { di campione, i batteri anaerobi sopravvivono per } 24 \text { ore a temperatura ambiente. } \\
\text { Per il trasferimento in laboratorio però è consigliabile l'uso di sistemi di trasporto per } \\
\text { anaerobi. Per quantità scarse di materiale è possibile aggiungere nella siringa soluzione } \\
\text { fisiologica sterile o brodo sterile prima di trasferire il tutto in un contenitore sterile. }\end{array}$ \\
\hline $\begin{array}{l}\text { BD Anaerobic Specimen Collector } \\
\text { BD, Div. of Beckton Dickinson and } \\
\text { Co. Rutherford, N,J. }\end{array}$ & $\begin{array}{l}\text { Provetta in vetro sotto vuoto che contiene all'interno una fiala fissata al tappo in } \\
\text { gomma. Il tampone inoculato viene inserito nella fiala interna e lo stantuffo viene } \\
\text { abbassato. La fiala interna si stacca dal tappo in gomma ed entra nella parte inferiore } \\
\text { della provetta esterna così che la parte terminale del tampone è in atmosfera di } \\
\text { anaerobiosi durante il trasporto. Un indicatore di riduzione è inserito sul fondo della } \\
\text { provetta esterna per segnalare un'eventuale esposizione all'ossigeno. }\end{array}$ \\
\hline
\end{tabular}

Tabella 2. Sistemi di trasporto per aerobi

\begin{tabular}{|c|c|}
\hline SISTEMI E FORNITORE & DESCRIZIONE \\
\hline $\begin{array}{l}\text { Sistema di trasporto con tampone } \\
\text { tipo "Culturette" } \\
\text { BBL Microbiology Systems } \\
\text { Cockeysville, Md. }\end{array}$ & $\begin{array}{l}\text { Dispositivo di raccolta sterile con sistema di trasporto costituito da provetta in plastica } \\
\text { contenente } 2 \text { tamponi con punta in rayon e un terreno di trasporto per prevenire } \\
\text { l'essicamento batterico e per mantenere il pH } \\
\text { N.B.: rompere sempre l'ampolla } \\
\text { Sistemi di trasporto simili sono prodotti da molte altre ditte }\end{array}$ \\
\hline Tampone in calcio-alginato & $\begin{array}{l}\text { Può essere tossico per alcuni ceppi di Neisseria gonorrhoeae, Ureaplasma urealyticum e per } \\
\text { alcune colture cellulari. }\end{array}$ \\
\hline Tamponi in cotone & $\begin{array}{l}\text { Gli acidi grassi residui possono inibire alcuni batteri e Chlamydia spp.. } \\
\text { Se il cotone è incollato o avvolto ad uno stick applicatore in legno, lo stick in legno può } \\
\text { interferire con alcuni test di identificazione di Ureaplasma e può inattivare HSV }\end{array}$ \\
\hline Tamponi in dacron & Utile per raccolte virali e per ricerca Streptococco di gruppo A \\
\hline $\begin{array}{l}\text { Tamponi naso-faringe - uretrali } \\
\text { (es. Calgiswab type IV; Spectrum } \\
\text { Diagnostics, Glenwood, III. ) }\end{array}$ & $\begin{array}{l}\text { Sottile, flessibile asta metallica con punta sottile che facilita la raccolta del campione, utile } \\
\text { in modo particolare per la raccolta di campioni nasofaringei, ricerca Bordetella pertussis, e } \\
\text { campioni uretrali maschili per ricerca } N \text {. gonorrhoeae }\end{array}$ \\
\hline $\begin{array}{l}\text { Contenitori sterili con tappo a } \\
\text { vite }\end{array}$ & $\begin{array}{l}\text { Usati per la raccolta di campioni di urine, escreati, feci, lavaggio broncoalveolare, biopsie. } \\
\text { Se il campione bioptico è piccolo aggiungere una piccola quantità di soluzione fisiologica } \\
\text { sterile nel contenitore. Non utilizzare mai formalina e non avvolgere in garza. }\end{array}$ \\
\hline Capsule Petri sterili & $\begin{array}{l}\text { Usate per campioni di capelli e annessi cutanei. Chiudere in sicurezza la piastra prima di } \\
\text { trasportare }\end{array}$ \\
\hline $\begin{array}{l}\text { Provette sterili ( con tappo a vite } \\
\text { in plastica o provette Vacutainer } \\
\text { senza additivi) }\end{array}$ & Usati per la raccolta di fluidi sterili, lavaggio broncoalveolare, drenaggi, o brush (spazzolato) \\
\hline $\begin{array}{l}\text { B-D urine-tubes } \\
\text { BD, Div. Of Becton Dickinson and } \\
\text { Co. Rutherford, N.J. }\end{array}$ & $\begin{array}{l}\text { Provetta Vacutainer contenente } 0.5 \mathrm{ml} \text { di conservante secco a base di acido borico in } \\
\text { formula bilanciata che consente di conservare i campioni di urina per } 48 \text { ore a temperatura } \\
\text { ambiente mantenendo la popolazione batterica a livelli comparabili a campioni refrigerati } \\
\text { per lunghi periodi. II conservante può essere tossico per alcuni patogeni urinari. }\end{array}$ \\
\hline $\begin{array}{l}\text { N.gonorrhoeae transport system } \\
\text { Jembec or Gono-Pack BBL } \\
\text { Microbiol. system }\end{array}$ & Piastre Petri con terreno di coltura e busta per incubazione con generazione di CO2 \\
\hline
\end{tabular}


Tabella 3. Sistemi di trasporto in rapporto alla tipologia del materiale da analizzare.

\begin{tabular}{|c|c|}
\hline TIPO DI CAMPIONE E RICERCA & METODO DI TRASPORTO \\
\hline Sangue & $\begin{array}{l}\text { Sistema di trasporto per sangue o provetta sterile con SPS, usare un sistema di } \\
\text { trasporto senza SPS se si sospetta Neisseria spp. }\end{array}$ \\
\hline CNS, CSF & Provetta sterile con tappo a vite \\
\hline $\begin{array}{l}\text { Apparato gastrointestinale: } \\
\text { feci } \\
\text { tampone rettale } \\
\text { lavaggio gastrico } \\
\text { aspirato duodenale } \\
\text { biopsia rettale }\end{array}$ & $\begin{array}{l}\text { Contenitore sterile tappo a vite, tampone con terreno Cary Blair o soluzione glicero- } \\
\text { salina tamponata (BGS) } \\
\text { Sistema di trasporto con tampone (per ricerche di parassiti utilizzare kit appositi) } \\
\text { Contenitore sterile tappo a vite, } \\
\text { Contenitore sterile tappo a vite } \\
\text { Contenitore sterile tappo a vite,se il campione è piccolo aggiungere soluzione } \\
\text { fisiologica sterile }\end{array}$ \\
\hline $\begin{array}{l}\text { Occhi: } \\
\text { scraping congiuntivale o corneale } \\
\text { fluido intraoculare }\end{array}$ & $\begin{array}{l}\text { Inviare il campione e inoculare direttamente nel terreno } \\
\text { Inviare il campione e inoculare direttamente nel terreno } \circ \text { utilizzare sistema di } \\
\text { trasporto per anaerobi }\end{array}$ \\
\hline $\begin{array}{l}\text { Tratto genitale femminile: } \\
\text { liquido amniotico, liquido Bartholin } \\
\text { cervice, uretra, vagina } \\
\text { endometrio } \\
\text { vulva }\end{array}$ & $\begin{array}{l}\text { Sistema di trasporto per anaerobi }(\mathrm{I}-2 \mathrm{ml}) \\
\text { Tampone di trasporto, o sistema trasporto per Chlamydia o sistema trasporto per } \\
\text { N.gonorrhoeae } \\
\text { Contenitore sterile tappo a vite o sistema di trasporto per anaerobi } \\
\text { Tampone di trasporto, o sistema trasporto per Chlamydia, slide per T.pallidum }\end{array}$ \\
\hline $\begin{array}{l}\text { Tratto genitale maschile: } \\
\text { tampone anale, uretra } \\
\text { epididimo } \\
\text { massaggio prostatico, liquido seminale } \\
\text { lesioni del pene }\end{array}$ & $\begin{array}{l}\text { Tampone di trasporto, o sistema trasporto per Chlamydia o sistema trasporto per } \\
\text { N.gonorrhoeae } \\
\text { Contenitore sterile tappo a vite o sistema di trasporto per anaerobi } \\
\text { Contenitore sterile tappo a vite o sistema di trasporto con tampone } \\
\text { Tampone di trasporto, o sistema trasporto per Chlamydia, slide per T.pallidum }\end{array}$ \\
\hline $\begin{array}{l}\text { Campioni per ricerca N.gonorrhoeae: } \\
\text { anale, cervicale, uretrale, vaginale }\end{array}$ & $\begin{array}{l}\text { Sistema di trasporto con tampone, inoculo diretto su MTM (Thayer Martin } \\
\text { modificato), sistema trasporto per N.gonorrhoeae }\end{array}$ \\
\hline $\begin{array}{l}\text { Tratto respiratorio inferiore: } \\
\text { biopsia polmonare } \\
\text { espettorato, espettorato indotto, } \\
\text { aspirato tracheale, lavaggio bronchiale o } \\
\text { broncoalveolare } \\
\text { brush bronchiale, biopsia transbronchiale } \\
\text { aspirato transtracheale, aspirato polmonare }\end{array}$ & $\begin{array}{l}\text { Contenitore sterile tappo a vite, se il campione è di scarsa quantità aggiungere } \\
\text { soluzione fisiologica sterile } \\
\text { Contenitore sterile tappo a vite, } \\
\text { Contenitore sterile tappo a vite, } \\
\text { Contenitore sterile tappo a vite, } \\
\text { Contenitore sterile tappo a vite o provetta sterile tappo a vite con I-2 ml di soluzione } \\
\text { fisiologica sterile }\end{array}$ \\
\hline $\begin{array}{l}\text { Tratto respiratorio superiore: } \\
\text { tampone da gola, naso, coltura orale, } \\
\text { nasofaringeo } \\
\text { fluido timpanocentesi, sinusaspirato, } \\
\text { lavaggionasale, aspirato nasale }\end{array}$ & $\begin{array}{l}\text { Tampone di trasporto } \\
\text { Sistema di trasporto per anaerobi } \\
\text { Contenitore sterile tappo a vite, }\end{array}$ \\
\hline $\begin{array}{l}\text { Fluidi sterili (escluso sangue, CSF, } \\
\text { urine): } \\
\text { pleurico, peritoneale, ascetico, sinoviale, } \\
\text { articolare }\end{array}$ & Contenitore sterile tappo a vite, Sistema di trasporto per anaerobi \\
\hline $\begin{array}{l}\text { Tessuto sottocutaneo e noduli o } \\
\text { ulcere cutanee, ferite o piaghe } \\
\text { superficiali: } \\
\text { essudati } \\
\text { campioni da scottature } \\
\text { materiale da lesione fungina superficiale biopsie }\end{array}$ & $\begin{array}{l}\text { Siringa sigillata senza ago } \\
\text { Contenitore sterile tappo a vite } \\
\text { Contenitore sterile tappo a vite,se il campione è di scarsa quantità aggiungere } \\
\text { soluzione fisiologica sterile }\end{array}$ \\
\hline $\begin{array}{l}\text { Ferite profonde, aspirati, tessuti: } \\
\text { ferite profonde o ascessi } \\
\text { aspirati da tessuti molli } \\
\text { tessuto osseo, biopsie tessuto cutaneo }\end{array}$ & $\begin{array}{l}\text { Sistema di trasporto per anaerobi } \\
\text { Siringa sigillata senza ago } \\
\text { Contenitore sterile tappo a vite,se il campione è piccolo aggiungere soluzione } \\
\text { fisiologica sterile }\end{array}$ \\
\hline $\begin{array}{l}\text { Urine: } \\
\text { raccolta spontanea, da catetere, svuotamento } \\
\text { vescicale } \\
\text { puntura soprapubica }\end{array}$ & $\begin{array}{l}\text { Contenitore sterile tappo a vite o apposita provetta con conservante } \\
\text { Sistema di trasporto per anaerobi o Siringa sigillata senza ago }\end{array}$ \\
\hline
\end{tabular}

\section{Il tampone (Bacteriological swab)}

Un sistema di raccolta e trasporto comune a molti campioni è il tampone (Swab), in fibre diverse e supporti diversi .

Le prime notizie riguardanti i tamponi risalgono all'ultimo decennio del secolo scorso e prendono in considerazione metodi curiosi come l'impiego di peli di capra, l'uso di tamponi di carta e anse di platino. Il passaggio dai tamponi di cotone allestiti estemporaneamente in laboratorio, a quelli for- 
niti dalle varie industrie è dovuto alla necessità di avere sempre disponibile un prodotto pronto all'uso, sterile e facilmente maneggiabile.

Attualmente i tamponi batteriologici sono costituiti da bacchette di supporto in materiale plastico, legno o filo metallico con all'estremità delle fibre assorbenti naturali come il cotone o sintetiche come nylon, dacron, rayon, calcio alginato, a volte impregnati con carbone, siero o frazioni di albumina.

Numerosi sono gli studi effettuati sul confronto tra i diversi materiali nel garantire la vitalità e la sopravvivenza dei microrganismi, in particolare quelli cosiddetti sensibili o difficili. (Es. Neisseria gonorrhoeae, Haemophylus influenzae ecc).

E' importante sottolineare che l'uso di una fibra piuttosto che un'altra è un elemento di criticità nella fase preanalitica e la scelta deve basarsi sulla conoscenza della correlazione esistente tra tipo di fibra e tipologia di materiale o di ricerca da effettuare.

A questo proposito va citato un lavoro pubblicato nel 1977 secondo il quale nei tamponi a secco la sopravvivenza variava da un $20 \%$ a zero dopo quattro ore dal prelievo. In particolare i tamponi in cotone-grezzo riducevano fortemente la vitalità batterica; tamponi in alginato o albumina erano meno tossici. L'utilizzo del terreno di trasporto consentiva la sopravvivenza di certi organismi fino a $24-48$ ore (5).

I tamponi di cotone possono contenere acidi grassi che possono risultare tossici per determinati organismi, mentre quelli con il calcio-alginato non dovrebbero essere usati per quei campioni dove si rende necessario l'uso di reagenti di estrazione o per indagini virali o per ricerca Chlamydia

Dacron e rayon sono da considerarsi fibre ideali per i tamponi in uso in microbiologia. (3)

Una pubblicazione del 1988 sui tamponi in calcio alginato (4) rileva l'interferenza di questo tipo di tamponi, non solo con la ricerca di Herpes simplex virus, Chlamydia trachomatis e Ureaplasma urealyticum ma anche la tossicità per le colture cellulari e per Neisseria gonorrhoeae.

Utilizzando invece tamponi in rayon e cotone si aveva una sopravvivenza di 6 ore circa, che migliorava ulteriormente con l'uso del terreno di trasporto Amies con carbone (indipendentemente dal tipo di tampone utilizzato)

I tamponi in cotone-grezzo a secco devono essere utilizzati solamente quando è possibile eseguire la coltura immediatamente dopo la raccolta del materiale; tamponi a secco con carbone, con albumina o calcio-alginato quando le colture si possono eseguire entro le 4 ore.

Per periodi di tempo maggiori devono essere utilizzati solo sistemi con terreno di trasporto.
In generale si può quindi dire che il tampone a secco svolge il solo ruolo di mezzo di raccolta, ma la sopravvivenza batterica, se il campione non viene processato subito, non è garantita.

I tamponi a secco non possono essere accettati qualora la consegna del campione e la semina siano ritardati rispetto al tempo di raccolta del materiale.

\section{I terreni di trasporto}

I microrganismi patogeni muoiono velocemente in ambiente secco e alcuni sono sensibili alle concentrazioni di ossigeno atmosferico. Per questo motivo si è cercato di creare terreni che consentissero la sopravvivenza dei microrganismi durante il trasporto.

Nel 1948 Moffet, Young e Stuart descrissero un terreno per il trasporto al laboratorio di campioni per la ricerca del gonococco. Nel 1954 Stuart, Toschach e Patsula studiarono ulteriormente questo metodo formulando un terreno semi-solido, non nutritivo, in soluzione tampone, altamente ridotto con un tampone di cotone impregnato di carbone per la raccolta, capace di mantenere efficacemente i campioni fino a 24 ore.

Prevenire l'essiccazione e l'ossidazione era di assoluta importanza per la sopravvivenza batterica. Queste regole furono decretate fondamentali per il trasporto dei campioni e applicabili ad una varietà di organismi fastidiosi e non, in uno studio condotto successivamente da Cooper nel 1957 che allargò l'uso del terreno di trasporto ai materiali delle alte vie respiratorie e ai patogeni enterici.

Nel 1967 Amies modificò la formula di Stuart aumentando il contenuto in agar, usando un tampone fosfato inorganico e sostituendo il tioglicollato di sodio con acido tioglicollico, mantenne il carbone ma preferì toglierlo dal tampone e introdurlo nel terreno. Queste modifiche servirono per limitare la sovracrescita dei coliformi.

Nel 1967 Cary and Blair modificarono ulteriormente il terreno di Stuart, sostituendo il glicerofosfato di sodio con fosfati inorganici.

Oltre che dall'essiccamento i terreni di trasporto sono essenziali per proteggere i microrganismi da:

- acidi grassi tossici

- condizioni sfavorevoli di pH

- effetti letali dell'ossigeno atmosferico

La loro formulazione permette di mantenere la vitalità batterica senza incrementarne la crescita $\mathrm{e}$ la moltiplicazione. Alcuni microrganismi patogeni tuttavia possono non sopravvivere in un terreno povero di elementi nutritivi mentre altre specie batteriche possono duplicarsi in un'ora se nel campione sono presenti fluidi corporei. 
Per la raccolta e conservazione dei campioni batteriologici i terreni più usati sono sostanzialmente tre:

- terreno di Stuart

- terreno di Amies

- terreno Cary - Blair

Il più usato è il terreno di Stuart, i cui componenti sono: cloruro di sodio, potassio, calcio e magnesio, fosfato di sodio e potassio, tioglicollato di sodio e agar, $\mathrm{pH}$ 7.3 . La presenza di tioglicollato di sodio abbassa il potenziale di ossidoriduzione (redox) del mezzo, permettendo una migliore conservazione dei batteri anaerobi. Il cloruro di sodio e di calcio consentono un controllo della permeabilità della cellula batterica e provvedono a bilanciare l'osmosi per preservare la vitalità cellulare. Il fosfato di sodio mantiene stabile il $\mathrm{pH}$. Il glicerofosfato di sodio presente nella formula originale di Stuart, ampiamente utilizzato dai coliformi come fonte di energia per la crescita, è sostituito nel terreno di Amies da una soluzione salina tamponata per evitarne la sovracrescita.

Una ulteriore modifica alla formula originale di Stuart è quella del terreno Cary-Blair dove viene migliorato il sistema tampone e il $\mathrm{pH}$ viene portato a 8.4. E' un terreno che può essere usato per il trasporto di patogeni enterici comprese Shigella, Vibrio cholerae, e Escherichia coli O157:H7. Per il valore alto di $\mathrm{pH}$ è il terreno di elezione per il trasporto e conservazione del $V$. cholerae.

Altri terreni di trasporto sono:

Alcaline peptone water (APW): può essere usata per la ricerca di V.cholerae, come brodo di arricchimento. Contiene enzimi digeriti di caseina e cloruro di sodio per il mantenimento dell'equilibrio osmotico e ha un $\mathrm{pH}$ relativamente alto (circa 8.4) che favorisce le condizioni ambientali per la crescita di Vibrio spp. È un terreno mediamente inferiore al Cary-Blair da usarsi quando quest'ultimo non è disponibile.

Soluzione glicero-salina tamponata (Buffered glycerol saline - BGS): è usato per Shigella, non va bene per il V.cholerae ed ha una breve durata una volta preparato. In linea generale per i terreni liquidi è più problematico il trasporto in quanto presentano rischi maggiori di fuoriuscita accidentale dai contenitori.

Attualmente i terreni di Stuart e Amies sono reperibili in commercio con o senza carbone. Il carbone se presente, viene inserito nel terreno per neutralizzare i prodotti metabolici tossici per il gonococco.

In Tabella 4 vengono messe a confronto le caratteristiche dei terreni citati.

\section{Dispositivo di trasporto tampone}

E' un sistema completo per il prelievo, trasporto e mantenimento dei campioni clinici per l'esame batteriologico, pronto all'uso e sterile. E' composto da un tampone per la raccolta del materiale su supporto in plastica o filo metallico (in alcuni casi regolabile) e da una provetta generalmente in polipropilene con terreno di trasporto (terreno liquido di Stuart o di Amies, o in agar gel con o senza carbone, Cary-Blair in agar gel) dove il tampone viene inserito dopo la raccolta. Il tutto è confezionato in buste singole sterili. Tra le diverse proposte commerciali, ve ne sono alcune (Copan Venturi Transystem e BD BBL Culture Swab) in cui la provetta è progettata secondo il sistema Venturi (tubo Venturi:dinamica fluidica) : la particolare strozzatura della provetta garantisce la fuoriuscita delle bolle d'aria che si formano nella rottura dell'agar quando viene inserito il tampone, inoltre, grazie ad essa la colonna di agar rimane bloccata nella parte inferiore sia prima che durante l'uso del sistema per cui non vi è possibilità che l'agar si stacchi e si sposti per capovolgimento (Figura I). La profondità della colonna di agar è anche una importante barriera fisica alla penetrazione dell'ossigeno ed il sistema in cui è concepito il tubo Venturi fa sì che vengano evitate eventuali rotture o la disintegrazione dell'agar durante l'uso (quando si estrae il tampo-

Tabella 4. Confronto tra le principali caratteristiche dei terreni

\begin{tabular}{|c|c|c|}
\hline Stuart's & Amies & Cary-Blair \\
\hline $\begin{array}{l}\text { Formulato originariamente per } \\
\text { N. gonorrhoeae } \\
\text { Alcuni bacilli gram negativi utilizzano il } \\
\text { glicerofosfato del terreno, questo provoca } \\
\text { una loro sovracrescita }\end{array}$ & $\begin{array}{l}\text { Modifica del terreno di Stuart } \\
\text { Sostituzione del glicerofosfato con } \\
\text { soluzione salina tamponata }\end{array}$ & $\begin{array}{l}\text { Simile allo Stuart's ma modificato per } \\
\text { campioni fecali } \\
\text { Sostituzione del glicerofosfato di sodio con } \\
\text { fosfati inorganici }\end{array}$ \\
\hline $\mathrm{pH} 7.3 \pm 0.2$ & $\mathrm{pH} 7.3 \pm 0.2$ & $\mathrm{pH}$ aumentato da 7.4 a 8.4 \\
\hline $\begin{array}{l}\text { Uso di carbone fissato al tampone } \\
\text { Il carbone crea difficoltà } \\
\text { nell'interpretazione del Gram. } \\
\text { Il carbone fissato al tampone è mal } \\
\text { accettato dai pazienti. }\end{array}$ & $\begin{array}{l}\text { Viene mantenuto il carbone ma } \\
\text { introdotto nel terreno }\end{array}$ & Elimina il carbone \\
\hline Valido per la maggior parte dei campioni & $\begin{array}{l}\text { Sistema di trasporto migliore per } \\
\text { molti microrganismi fastidiosi }\end{array}$ & $\begin{array}{l}\text { Valido per campioni di feci } \\
\text { Particolarmente indicato per la ricerca di } \\
\text { Shigella, Vibripo.cholerae }\end{array}$ \\
\hline
\end{tabular}


ne). Con i sistemi di trasporto convenzionali (provette senza strozzatura) si possono invece avere risultati non corretti dovuti ad una diluizione del campione e un maggiore rischio di contaminazione per l'operatore e l'ambiente.
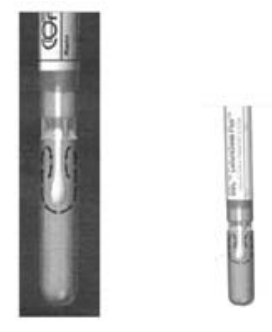

Venturi Giovanni Battista (1746-1822) fisico e ingegnere italiano, discepolo di L.Spallanzani. realizzò il venturimetro (o tubo di Venturi) per la misura della velocità dei fluidi in base alla loro pressione. In particolare dimostrò che una diminuzione di sezione (strozzatura) in un condotto percorso da un fluido in moto permanente provoca un aumento di velocità e una corrispondente diminuzione della pressione nella sezione del tubo ridotta. E' possibile perciò in un tubo opportunamente sagomato (detto tubo di Venturi o venturimetro) misurare la portata dei fluidi in condotte forzate.

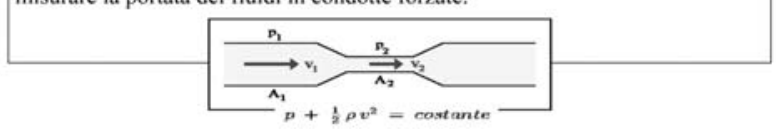

Figura I. Provetta progettata secondo il sistema Venturi

\section{Controllo di qualità dei terreni di trasporto e dei sistemi di trasporto tampone}

I produttori devono dichiarare, nei certificati di qualità che accompagnano il prodotto, la conformità dello stesso alle raccomandazioni dell'NCCLS M22 A per quanto riguarda sterilità del tampone e del terreno,i parametri fisici e chimici del terreno di trasporto (correlati alla capacità del terreno stesso di mantenere la vitalità batterica), i test a cui sono stati sottoposti , i "performance test" con uso di ceppi ATCC (American Type Culture Collection) ed i relativi risultati, la data di scadenza, le modalità di conservazione $\mathrm{e}$ d'uso del terreno ed il metodo di sterilizzazione utilizzato per il prodotto finale. Il laboratorio deve conservare una copia dei certificati di qualità dei terreni in uso, rilevando eventuali non conformità e segnalandole.

\section{Test di sterilità}

Un numero rappresentativo di tamponi di ogni singolo lotto viene testato dal produttore per la sterilità, aggiungendo alle provette con tampone del TSB (Tryptone Soy Broth) o Fluid Thioglycollate Medium (FTM). Le provette vengono incubate a $25^{\circ} \mathrm{C}$ e a $37^{\circ} \mathrm{C}$ per 14 giorni e controllate quotidianamente. La sterilità del lotto viene dichiarata solo se non vi è crescita dopo 14 giorni di incubazione. Vengono anche utilizzati dei tests ad indicatori chimici e biologici per monitorare le varie fasi di produzione.

\section{Test per la carica batterica non vitale}

La natura organica dell'agar lo rende un ottimo substrato per la moltiplicazione batterica. Ciascun lotto di agar è accompagnato da un certificato di analisi del produttore con la carica batterica . Questo materiale viene poi inserito nei vari terreni usati in microbiologia. La maggior parte dei terreni è in piastra Petri o in provette e non viene mai osservata al microscopio con colorazione di Gram. Il terreno è garantito nella sterilità dal passaggio in autoclave così che la carica vitale non è un problema. Diverso è il caso in cui l'agar, utilizzato nel terreno di trasporto, viene mescolato con il campione del paziente nella preparazione di un vetrino per l'osservazione al microscopio dopo colorazione di Gram. In questo caso la conta batterica del paziente si può sommare a quella dell'agar. Esistono degli agar altamente purificati come l'Agar Nobile e l'Agarosio con una carica vitale inferiore o quasi nulla ma non possono essere utilizzati per i terreni di trasporto a causa delle loro peculiari caratteristiche. Si utilizzano quindi $\mathrm{i}$ test di colorazione al Gram per individuare il lotto di agar migliore, con una carica vitale più bassa possibile.Nei certificati di qualità dei prodotti si dichiara il numero di batteri non vitali riscontrati alla colorazione di Gram. Non dovrebbero essere riscontrati più di 2 batteri per 10 campi microscopici.

\section{Test per i parametri fisici e chimici}

Ogni lotto dei sistemi di trasporto tampone è testato per il pH, e solidità del gel.

La scelta del tipo di agar per la produzione del terreno di trasporto è fondamentale non solo per la carica batterica non vitale ma anche per una corretta solidità del gel. Questo per mantenere una colonna profonda stabile, intatta e senza alcuna rottura o bolla d'aria. Solo una colonna intatta di agar gel impedisce la penetrazione dell'ossigeno atmosferico tossico o nocivo agli anaerobi e a batteri difficili quali la Neisseria gonorrhoeae ed è assolutamente essenziale per poter ritrovare i batteri patogeni dopo $24-48$ ore. La solidità della gelificazione dell'agar è un fattore critico: non può essere semplicemente aumentata aggiungendo più grammi di agar poiché un eccesso di agar è un inibitore batterico.Gli agar purificati nelle loro proprietà hanno una gelificazione meno solida.

Oltre a questo, il processo di sterilizzazione mediante irradiazione ionizzante a cui è sottoposto il prodotto finito, causa una notevole riduzione nella solidità dell'agar gel e la colonna può rompersi. Questi sono i fattori che in pratica escludono la possibilità di utilizzare agar purificati nella produzione di terreni di trasporto con tampone. 


\section{Tests di performance}

Ogni lotto è rigorosamente testato con un'ampia serie di specie batteriche (ceppi ATCC o NCTC) per assicurarne un adeguato ritrovamento, ad esempio per il terreno di Stuart-Amies $(\mathrm{pH} 7.3 \pm$ 0.2) vengono utilizzati Streptococcus pyogenes ATCC 19615 e Neisseria gonhorroeae 43096, per il Cary Blair (pH $8.4 \pm 0.2$ ) Campylobacter jejuni 33291, Shigella flexneri 12022, Yersinia enterocolitica 9610 (2) .

\section{Dispositivi di trasporto tampone: quali garan- zie per la qualità della fase preanalitica?}

E' percezione comune che i microrganismi sopravvivano egualmente bene su tamponi di composizione simile, prodotti da differenti industrie: su questo aspetto sono stati condotti numerosi studi per valutare la performance dei vari dispositivi in commercio non solo per quanto riguarda gli aspetti intrinseci ai sistemi di trasporto (es. contenitore, terreno, tipo di tampone) ma anche tutti quei fattori esterni (temperatura, tempo di conservazione, modalità di semina) che possono avere un ruolo significativo nel recupero dei microrganismi presenti nel campione.

Particolarmente interessante ad esempio è il lavoro di Perry J.L. et al. (1997) sui fattori che influenzano la ricerca dei microrganismi con i dispositivi di trasporto tampone e sulla complessità della loro valutazione (6). Perry J.L. confronta tre dispositivi di trasporto: Port a Cul Tubes (PAC, Becton Dickinson), Culturette EZ (EZ; Becton Dickinson) e Copan Venturi Transystem Amies gel senza carbone (CAG; Copan Diagnostics) dichiarati come sistemi adatti alla ricerca di aerobi ed anaerobi, con una capacità di mantenimento della maggior parte dei microrganismi fino a 48 ore a temperatura ambiente. E' dimostrato che gli anaerobi e gli aerobi "difficili o sensibili" sono gli organismi chiave per valutare la capacità di un sistema trasporto tampone, di mantenere la carica batterica, pertanto i tre dispositivi vengono testati singolarmente con 11 ceppi ATCC di cui 7 anaerobi e 5 aerobi.

L'inoculo è stato effettuato immergendo il tampone nella sospensione standardizzata del ceppo ATCC per 5 secondi e poi nel corrispondente dispositivo di trasporto che veniva conservato a temperatura ambiente. La sopravvivenza batterica è stata valutata quantitativamente dopo 0,24 e 48 ore dall'inoculo mediante conta delle colonie in piastra. Per la conta, il tampone veniva rimosso dal dispositivo, immerso in $1 \mathrm{ml}$ di soluzione salina ed il tutto trattato al vortex per 30 secondi. Il tampone veniva quindi estratto, dopo averlo premuto sulle parete della provetta, ed eliminato. La semina in piastra veniva effettuata con ansa cali- brata o pipetta sterile distribuendo attentamente il materiale su tutta la superficie dell'agar.

La procedura utilizzata è stata studiata per eliminare le variabili di una semina diretta che possono influenzare la ricerca, quali ad esempio la diversa porosità del tampone, l'attaccamento dei microrganismi alle fibre e il trasferimento meccanico sulla superficie dell'agar.

Per gli organismi testati con Culturette EZ e' stata rilevata,dopo 24 ore, una carica batterica inferiore dell' $1 \%$ rispetto all'inoculo iniziale, Port a $\mathrm{Cul}$ risulta leggermente superiore, migliore è la ricerca con Copan Amies gel. Lo studio evidenzia che la maggiore differenza tra Culturette EZ e gli altri dispositivi sta nel materiale del tampone. Notevole è la differenza di assorbimento. Nei 5 secondi di immersione del tampone nella soluzione di inoculo (tempo ragionevole per il prelievo del materiale) EZ assorbe $0,028 \mathrm{ml}$ contro i 0,120 $\mathrm{ml}$ degli altri due sistemi. Un precedente lavoro su EZ si usava uno schema di inoculo che prevedeva un contatto del tampone con la sospensione di organismi di minimo 3 minuti. Questo però nella pratica clinica è un tempo non realistico.

Nelle conclusioni si sottolinea come uno studio comparativo di questa natura non possa essere paragonato con i campioni clinici senza l'introduzione delle variabili incontrollabili. Infatti i campioni clinici variano in viscosità e contengono cellule e componenti chimici che possono agire da nutrienti o essere tossici e spesso si tratta di campioni polimicrobici. Tutti questi fattori possono influenzare la vitalità degli organismi così come l'eventuale presenza di sangue o materiale purulento,perché contrastano il fenomeno di essiccamento e l'effetto dannoso dell'esposizione all'aria.

Altrettanto interessante è il confronto di tre sistemi di trasporto tampone di diverso produttore ma con identico terreno: liquid modified Stuart's transport medium di Campos J.M. et al (2000)(7) ,in cui vengono confrontate le capacità di sopravvivenza di due isolati clinici di N.gonorrhoeae, del ceppo ATCC 19424 (NG), di N.meningitidis ATCC 13077 (NM), Streptococcus pneumoniae ATCC 27336 (SPN), S.pyogenes ATCC 19615 (SPY) e di H.influenzae ATCC 35540 (HI) in tre diversi tamponi conservati a temperatura ambiente dopo l'inoculo e testati al tempo 0, 6, 24 e 48 ore.

I tamponi sono: BBL Culture Swab ( $\mathbf{C}$, Becton Dickinson tampone prodotto da Copan), CULTURETTE (BD, Becton Dickinson) e STARswab (S, Starplex Scientific). La procedura utilizzata è quella di estrazione al vortex e semina su piastra come descritto nel lavoro precedente. I risultati riportano una minima differenza tra $\mathrm{i}$ tre sistemi 
di trasporto tampone nelle prime 6 ore di conservazione. Per periodi prolungati invece le differenze aumentano maggiormente, pertanto ai laboratori dove la semina del materiale viene effettuata in tempi superiori alle 6 ore viene consigliato di prestare molta attenzione a quanto segnalato nel lavoro.

\section{Dispositivi di trasporto tampone: la temperatura di conservazione}

Possiamo sicuramente affermare che l'utilizzo dei dispositivi di trasporto tampone, oggi così diffuso, ha incrementato notevolmente l'interesse per la qualità della fase preanalitica e lo si può dedurre dai numerosi lavori di valutazione pubblicati nell'ultimo decennio.

Vediamo però in questi ultimi anni una crescente attenzione ad uno dei fattori esterni al sistema:

"la temperatura di conservazione dei microrganismi con i dispositivi di trasporto tampone".

Sorprendenti sono infatti i risultati di un lavoro di Perry J.L. del 2001(8). Nello studio vengono valutati gli effetti protettivi di vari dispositivi di trasporto e della temperatura di conservazione su 116 ceppi clinici di S.pneumoniae (61), N.gonorrhoeae (11), N.meningitidis (5) e H.influenzae (39). Per quanto riguarda i dispositivi si utilizzano:

- un tampone a secco (DRY) rimosso da Culturette (Becton Dickinson), ridotto in lunghezza e inserito post-inoculo senza romper l'ampolla del dispositivo

- un dispositivo Culturette usato correttamente (CUL)

- un dispositivo Copan Amies gel (GEL; Copan Diagnostics)

- un dispositivo Copan liquid Stuart's (COS).

I tamponi inoculati vengono conservati sia a temperatura ambiente (TA) che a $4{ }^{\circ} \mathrm{C}$. A diversi intervalli di tempo post-inoculo, fino ad un massimo di 72 ore, si eseguono le semine e la sopravvivenza batterica viene valutata con conta delle colonie in piastra.

I risultati dimostrano che il tampone a secco, come ci si può aspettare praticamente, non mantiene la vitalità degli organismi in nessun caso. I dispositivi con terreno di trasporto e conservati a $4^{\circ} \mathrm{C}$ consentono la migliore sopravvivenza di quegli organismi cosiddetti sensibili o difficili. In più i dispositivi con Amies gel e Liquid Stuart's consentono il ritrovamento di tutti i microrganismi 24 ore post-inoculo, ma con i campioni conservati a temperatura ambiente viene notata una significativa diminuzione.

Organismi vitali si ritrovano dopo $48-72$ ore solamente dai tamponi conservati a $4{ }^{\circ} \mathrm{C}$.

Gli autori suggeriscono nelle conclusioni che la sopravvivenza prolungata nel tempo, dei microrganismi "difficili", è legata alla loro conservazione a $4^{\circ} \mathrm{C}$, in contrasto con le linee guida che considerano deleteri gli effetti della refrigerazione sulla vitalità di questi patogeni.

Le storiche disposizioni per il trasporto/conservazione dei campioni possono non riflettere accuratamente le capacità dei moderni dispositivi. L'estrapolazione di questi risultati a campioni non raccolti con tampone richiede però ulteriori studi. Poiché le nuove tecnologie forniscono l'opportunità per ridefinire il metodo di recupero o ricerca degli organismi di interesse, la standardizzazione dei test di controllo di qualità e criteri di accettabilità diventerà importante per assicurare un più elevato livello di cura ai pazienti.

La definizione di linee guida per il controllo di qualità dei mezzi di trasporto sarà d'aiuto nella standardizzazione delle performance di questi dispositivi.

\section{Anno 2002 - NCCLS NEWS}

L'anno 2002 può considerarsi a tutti gli effetti una data storica, come riferito in premessa, per quanto riguarda la temperatura di trasporto.

L'NCCLS pubblica il documento M40-P:

Quality Control Standards of Microbiological Transport Systems ; Proposed Standard (9) che comprende gli standards per valutare la performance dei dispositivi di trasporto con tampone.

\section{Documento M40-P}

Nella prefazione di questo nuovo e recente documento dell'NCCLS, oltre ai riferimenti storici,si riportano le motivazioni che hanno portato alla realizzazione di uno standard per il controllo di qualità dei mezzi di trasporto.

Negli Stati Uniti, i requisiti dei prodotti di base per i dispositivi sanitari, compresi i dispositivi per la diagnostica in vitro (IVD) sono stati stabiliti dal Medical Device Amendments del 1976. Questa legislazione ha dato al Food and Drug Administration (FDA) l'autorità per regolare i dispositivi sanitari, con notifica e approvazione, prima della vendita e sviluppare i requisiti di conformità dei prodotti (Good Manufactoring Practices). Fra questi è compresa l'esecuzione dei test di controllo di qualità del prodotto prima della distribuzione. A ciascun produttore è richiesto di stabilire il tipo di test che deve eseguire, i criteri su cui si basa l'accettabilità del prodotto e l'uso a cui è destinato.

L'Unione europea ha recentemente adottato le Medical Device Directive 93/42/EEC e le direttive per $\mathrm{i}$ dispositivi per diagnostica in vitro 
98/79/EC che hanno requisiti molto simili a quelli degli Stati Uniti. Le direttive comprendono le disposizioni per utilizzare gli standard accordati come metodo di dimostrazione di conformità ai requisiti stabiliti. Inoltre il FDA ha recentemente formalizzato l'uso di questi standard da parte dei produttori per dimostrare la performance del prodotto come obbligo in fase di prevendita.

Questo standard è stato sviluppato grazie alla cooperazione della Commissione di Microbiologia dell'NCCLS e la sua sottocommissione per il controllo di qualità dei dispositivi di trasporto microbiologici e il suo corrispondente del Duetsches Institut für Normung (DIN).

Rappresentanti dell'NCCLS e del DIN hanno partecipato allo sviluppo dello standard di ciascuna delle rispettive organizzazioni. Si pensa che questo sforzo porterà ad un accordo internazionale di questo importante standard di microbiologia.

Prima della produzione di questo documento, non c'era una procedura standard riconosciuta per la determinazione dell'efficacia dei dispositivi di trasporto microbiologici.

Di conseguenza, i produttori non avevano il beneficio di linee guida esterne e standards per misurare le caratteristiche di performance dei loro prodotti, e dovevano fare affidamento unicamente a loro protocolli interni.

Esistono in commercio una varietà notevole di dispositivi e sistemi di trasporto microbiologici.

Lo scopo di questo documento è fornire uno standard per mettere in grado produttori ed utilizzatori di valutare sistematicamente l'efficacia dei dispositivi, garantire standards di performance, consentire una validazione interna dell'efficacia del prodotto.

\section{Scopo del documento}

Questo standard fornisce a produttori ed utilizzatori di dispositivi di trasporto, dei criteri per aiutarli nell'approvvigionamento di prodotti sicuri per il trasporto dei campioni clinici. Le industrie produttrici devono dichiarare se le caratteristiche di performance di un particolare prodotto soddisfano gli standard di performance specificati dallo standard . In più devono dichiarare se è necessario o meno aggiungere altri test prima dell'uso di un particolare prodotto.

Da sottolineare che il controllo di qualità consiste in una valutazione delle caratteristiche di performance di un dispositivo di trasporto completo e non dei componenti individuali.

Ci sono molteplici variabili implicate nella produzione di un dispositivo di trasporto che comprendono, ma non si limitano, il contenitore, il terreno di trasporto, il dispositivo di raccolta, il confezionamento e l'atmosfera.
Il documento non intende fornire informazioni sullo sviluppo del prodotto, ma piuttosto fornire a chi usa il dispositivo la sicurezza che il produttore dichiari di aver seguito dei tests standardizzati e dei criteri di accettabilità. Non riguarda le tecniche di produzione del dispositivo di trasporto ma è centrato sui metodi per i test di controllo di qualità e sui criteri di accettabilità per fornire un prodotto idoneo all'analisi dei campioni clinici.

I clinici, i laboratoristi, i pazienti aspettano prodotti che incontrino i più alti standards delle pratiche di laboratorio. Questo documento favorirà il raggiungimento di questa meta. E' al di là dello scopo di indirizzare il design del dispositivo, è fondamentale che il design favorisca un uso corretto e che i laboratoristi selezionino i dispositivi che meglio si prestano a seconda delle necessità. Non si prefigge una discussione sulle condizioni di trasporto, ma riconosce che la temperatura ha un significativo effetto sulla conservazione dei microrganismi nei vari dispositivi utilizzati. Sulla base degli studi fatti che hanno comparato performance di dispositivi di trasporto inoculati con diversi microrganismi sia a temperatura ambiente $\left(20-25^{\circ} \mathrm{C}\right)$ che a $4-8^{\circ} \mathrm{C}$ sottolinea che la migliore è quest'ultima, suggerendo che le raccomandazioni attuali del trasporto a temperatura ambiente non rappresentano l'ottima temperatura di mantenimento per la massima conservazione dei campioni microbiologici. Si devono incoraggiare $\mathrm{i}$ produttori ad eseguire controlli di qualità dei dispositivi di trasporto microbiologici, sia a temperatura ambiente che a $4-8^{\circ} \mathrm{C}$ e a specificare ciò nel foglietto illustrativo interno. Questo consentirà di assicurare ai laboratori che vorranno convalidare il trasporto dei campioni a $4-8^{\circ} \mathrm{C}$ che il prodotto è stato testato con controlli per quella temperatura.

\section{Anno 2003 - Lo stato dell'arte}

Il recente documento M40-P dell'NCCLS può essere definito lo "starting point" per il Controllo di Qualità dei dispositivi di trasporto: vi sono già due lavori di comparazione eseguiti secondo le indicazioni in esso riportate, pubblicati in maggio 2003, di Arbiques J e coll. E di Perry JL rispettivamente nei quali si valutano dispositivi (6 nel primo caso e due nel secondo) di produttori diversi, secondo la procedura seguente:.

- inoculo standardizzato di ceppi ATCC aerobi ed anaerobi,(tempo di inoculo standardizzato)

- temperatura di conservazione sia ambiente (20$25^{\circ} \mathrm{C}$ ) che $4^{\circ} \mathrm{C}$

- semina in piastre al tempo 0,24 e 48 ore con metodo di eluizione del tampone con vortex (Swab elution) e semina diretta (roll plate). 
Sono anche stabiliti precisi criteri di accettabilità per entrambi i metodi di semina:

roll-plate - $>5 \mathrm{CFU}$ (vitalità) $<1 \log$ (aumento)

eluizione del tampone- $<1 \log$ aumento a $4-8^{\circ} \mathrm{C} /$

$<3 \log$ diminuzione.

I risultati (in entrambi i lavori con tutti i dispositivi testati) supportano l'affermazione di altri lavori precedenti e sottolineano, come sopra riportato,che la temperatura di conservazione di $4-8^{\circ} \mathrm{C}$ è chiaramente superiore nel garantire la sopravvivenza per tempi prolungati della maggior parte degli organismi difficili.

Le raccomandazioni di mantenere i dispositivi di trasporto tampone a temperatura ambiente durante il trasporto devono essere riviste all'evidenza dei dati riscontrati.

\section{Contenitori e terreni per la ricerca di microrganismi nel sangue}

Come è noto l'emocoltura è uno degli esami più importanti della microbiologia sia per la sua rilevanza clinica (la sepsi è una delle più gravi sindromi infettive) che per l'importanza diagnostica ed epidemiologica (quello che viene isolato è nella maggioranza dei casi, l'agente eziologico vero dell'infezione).

Dalla prima emocoltura sperimentale indotta, inoculo di sangue di animali con carbonchio in conigli sani il progresso tecnologico porta, verso gli anni '50, ad una standardizzazione di terreni e contenitori specifici per questo esame. Gli ultimi anni vedono poi un utilizzo sempre più allargato di apparecchiature sofisticate automatiche e affidabili in grado di rilevare in modo continuo la presenza di microrganismi nel sangue inoculato negli appositi brodi di coltura

Le linee guida generali (1) descrivono vari terreni e tecniche di coltura del sangue.

I terreni, in questo caso, non svolgono solo la funzione di trasporto del sangue ma contengono tutti i principi nutritivi necessari allo sviluppo dei microrganismi eventualmente presenti.

\section{Considerazioni generali:}

1. il terreno di coltura dovrebbe contenere SPS (polyanetholesulfonate) in concentrazione da 0.025 a $0.5 \%$ ) tranne i casi in cui si sospetta la presenza di meningococco o gonococco.

SPS è un anticoagulante che inibisce l'attività battericida del siero verso molti batteri patogeni, inibisce la fagocitosi, inattiva il complemento e neutralizza i lisozimi e gli aminoglicosidi.

Nella raccolta del sangue per l'emocoltura alcuni anticoagulanti non devono essere usati.
L'ossalato di ammonio inibisce la crescita della maggior parte dei microrganismi.

Il citrato di sodio inibisce gran parte dei gram positivi. L'SPS è l'anticoagulante che esprime meno tossicità e favorisce una sopravvivenza batterica a lungo In letteratura però è riportato che SPS può inibire alcuni ceppi di Neisseria spp.)

2. il rapporto sangue - terreno raccomandato è da 1: 3 a $1: 10$

3. inoculare il sangue direttamente nel terreno

4. volumi di sangue:

- pazienti pediatrici da 0.5 a $3 \mathrm{ml}$ di sangue per flacone di terreno

- adulti da 10 a $30 \mathrm{ml}$ di sangue da suddividere eventualmente nei due diversi terreni (aerobi ed anaerobi)

- quando si usa il sistema ISOLATOR utilizzare le diverse provette in dotazione $(10 \mathrm{ml}$ di sangue per adulti; $1,5 \mathrm{ml}$ per pediatrici)

\section{Terreni e sistemi che si possono utilizzare} per l'isolamento di batteri aerobi e anaerobi facoltativi:

a) terreni liquidi

- Tryptic o TSB

- Brodo peptone supplementato

- BHI (Brain Hearth infusion)

- Brucella Broth

- Columbia Broth

b) sistema bifasico

- Septi - Chek (Roche Diagnostics) con agar slide

- Becton Dickinson Vacutainer agar slant

- Bottiglie Castaneda con TSB (fase liquida) e TSA (fase solida)

c) Sistema lisi-centrifugazione ISOLATOR

(Wampole Laboratories)

d) Terreni per aerobi- anaerobi facoltativi da usarsi con sistemi automatici

- Brodi BACTEC (K-DVE Plus/F aerobic o anaerobic o Peds Plus- flaconi per pazienti pediatrici,; Becton Dickinson Div. Instrument Systems -BDDIS, Sparks, MD). I flaconi contengono resine per l'adsorbimento degli eventuali antibiotici presenti nel sangue.

- BacT/Alert (Organon TeKniKa) aerobic

- Vital Aer e Vital Ana - BioMerieux

e) Terreni specifici per anaerobi:

Liquidi:

- Brodo Thioglycollato

- Thiol broth

- Brood BHI per anaerobi

Per sistemi automatici:

- Brodi BACTEC Lytic/F anaerobic BDDIS)

- BacT/Alert (Organon Teknika) anaerobic 
- Dispositivo di lisi-centrifugazione (ISOLATOR; Wampole) per inoculo di agar o brodi per anaerobi

Terreni e tecniche che si possono utilizzare per l'isolamento di miceti:

- Biphasic vented BHI medium

- Vented conventional blood culture bottle

- Dispositivo di lisi-centrifugazione (ISOLATOR; Wampole) per inoculo di terreni per miceti

- Brodi BACTEC (BDDIS)

Terreni e tecniche che si possono utilizzare per l'isolamento di micobatteri:

- flaconi per emocoltura per sistemi radiometrici ( BACTEC 13A; BDDIS)

- Dispositivo di lisi-centrifugazione (ISOLATOR; Wampole) per inoculo di terreni per micobatteri

- Septi- Chek - AFB (Roche Diagnostics) sistema bifasico

- Flaconi BACTEC Myco/F Lytic

\section{Emocoltura con sistemi automatici}

Le apparecchiature automatiche prevedono l'uso abbinato di flaconi specifici per la ricerca di batteri aerobi, anaerobi, di micobatteri e miceti. Il sangue viene inoculato direttamente nei flaconi (contenenti il brodo di coltura sottovuoto), seguendo le modalità descritte dai produttori; questi vanno inseriti il prima possibile negli strumenti per l'incubazione e il monitoraggio continuo della crescita batterica. Sono disponibili in commercio set di raccolta specifici per il prelievo diretto vena paziente- flacone di coltura. In alternativa si può prelevare il sangue in provette con anticoagulante (SPS) e trasportarlo al laboratorio, dove il personale provvede all'inoculo del flacone.

I flaconi contengono terreni di coltura arricchiti (estratti di soia,lievito e tessuto animale, vitamine, zuccheri,sali minerali) o selettivi per ricerche particolari. Possono contenere delle sostanze particolari (Ecosorb per BacT/Alert ) o resine (ad adsorbimento anionico e a scambio cationico per Brodi BACTEC) per catturare gli antibiotici eventualmente presenti nel sangue del paziente e sono diversificati a seconda del tipo di ricerca. Vi sono in commercio flaconi per aerobi, anaerobi, flaconi con terreni altamente selettivi per lieviti, funghi e muffe, o per la ricerca di micobatteri.

In alcuni terreni (es. Lytic o Myco/F Lytic della serie Bactec) vi possono essere agenti litici come la saponina che ha la funzione di lisare le cellule del sangue liberando eventuali microrganismi fagocitati o nascosti nelle cellule stesse.
I flaconi per sistemi automatici possono essere utilizzati anche per la ricerca di microrganismi nei liquidi biologici quali pleurico, peritoneale, ascitico, pericardico, biliare.

I flaconi sono pronti all'uso, vanno ispezionati prima dell'uso per verificare l'assenza di danni, contaminazioni o deterioramenti. Si conservano a temperatura ambiente, a riparo dalla luce solare diretta fino alla data di scadenza riportata in etichetta.

L'inoculo di sangue deve rispettare le quantità specificate per ciascun tipo di flacone.

Certificati di controllo di qualità accompagnano i prodotti e indicano i ceppi ATCC testati secondo le norme NCCLS e i range dei tempi di individuazione dei microrganismi.

\section{Emocolture manuali}

Sistema bifasico: il sistema consta di un flacone contenente il brodo di coltura sottovuoto in comunicazione con un cilindro contenente un supporto (slide) su cui sono stratificati 2 o 3 tipi di terreno solido a seconda dei casi. Il supporto dello slide viene avvitato direttamente sopra il flacone.

Nel brodo, seminato con il campione in esame, si moltiplicano i batteri eventualmente presenti; sui terreni dello slide, che vengono inoculati capovolgendo periodicamente il sistema in modo che il brodo li bagni completamente, si possono sviluppare colonie isolate. La presenza fra $\mathrm{i}$ terreni del sistema di uno ad uso generale (TSA o Agar cioccolato) permette il rilevamento di tutti i microrganismi presenti o il rilevamento precoce delle contaminazioni nella ricerca di micobatteri. Vi sono in commercio flaconi con terreni diversi, anche per uso pediatrico con o senza resine di adsorbimento. La fase liquida può essere costituita da TSB o BHI o brodo Thioglicollato o Schaedler. Molti terreni sono addizionati di CO2. Generalmente la quantità di sangue richiesta va da 3-5 $\mathrm{ml}$ per i flaconi pediatrici, 8-10 $\mathrm{ml}$ per gli altri.

I flaconi inoculati devono essere inviati al laboratorio il prima possibile, per l'applicazione dello slide e incubazione.

Per una ricerca allargata non è consigliato l'uso di un singolo brodo.

Sistema Isolator: il sistema utilizza una provetta contenente una miscela di reagenti in grado di lisare le cellule ematiche senza ledere la vitalità dei microrganismi eventualmente presenti. Il concentrato di microrganismi ottenuto per centrifugazione, può essere seminato sui diversi terreni a seconda del tipo di ricerca. I componenti presenti nella provetta includono SPS come anticoagulante, saponina (sostanza in grado di lisare i globuli 
rossi e i globuli bianchi) e glicole propilenico.

Nella provetta si raccolgono $10 \mathrm{ml}$ di sangue del paziente, si mescola bene per inversione,si invia al laboratorio. La processazione del campione deve essere effettuata entro le 8 ore dalla raccolta. Per pazienti pediatrici usare le provette ISOLATOR da 1,5 ml; in questo caso non è necessaria la centrifugazione.

\section{Contenitori e provette sterili}

Nelle linee guida generali per la raccolta di diversi campioni biologici viene indicato il contenitore sterile, o provetta sterile con tappo a vite. In commercio vi è una vasta scelta di questi contenitori perché numerosi sono i produttori e/o distributori. In generale possiamo dire che il contenitore sterile serve per la raccolta di campioni biologici liquidi quali urine o altri fluidi biologici, escreati , cateteri o biopsie di tessuto. Il coperchio non deve creare aerosol quando rimosso pertanto sono preferibili i contenitori con tappo a vite. Per facilitare la raccolta del materiale sono preferibili contenitori ad apertura larga.

Diverse sono le materie prime utilizzate per questi contenitori. Per lo più si trovano in commercio in polistirolo o in polipropilene. I tappi sono generalmente in polietilene o polipropilene. In alcuni è presente una superficie di scrittura o etichetta e una scala graduata esterna. La capacità e forma del contenitore può essere diversa a seconda delle necessità. ( da un minimo di 15 a 200 ml.) Sono contenitori monouso, a volte in confezione singola; la sterilità è dichiarata dal produttore con certificato allegato dove è stabilita la data di scadenza e il metodo utilizzato.

\section{Polipropilene (PP):}

resina termoplastica traslucida ottenuta dalla polimerizzazione del propilene. Materiale resistente e flessibile, fa barriera all'umidità, resiste ad oli,solventi, acidi e basi forti e a temperature fino a $130^{\circ} \mathrm{C}$ e a $-198^{\circ} \mathrm{C}$. $\mathrm{Ha}$ ottime caratteristiche di resistenza chimica ( a temperatura ambiente non viene sciolto da alcun solvente) Viene impiegato nella produzione di articoli stampati, fibre, pellicole, funi e giocattoli. In campo medicale viene usato per provette e contenitori in genere.E' completamente inerte nei confronti dei materiali con cui viene a contatto.

Polistirolo (PS):

resina sintetica rigida (polimero) atossica e incolore ottenuta dalla polimerizzazione dello stirene. Ottima stabilità dimensionale e buona resistenza alle soluzioni acquose ma resistenza molto limitata ai solventi, in particolare se a base di idrocarburi aromatici e clorurati. Resiste bene fino a $165^{\circ} \mathrm{C}$ e a $-198^{\circ} \mathrm{C}$. Utilizzato nello stampaggio ad iniezione, per la produzione di laminati ed oggetti plastici in genere. In campo medi- cale viene usato nello stampaggio di provette e contenitori qualora venga richiesta un'ottima trasparenza. A temperatura ambiente i prodotti in PS sono rigidi e quindi possono fessurarsi o rompersi se cadono da un baco di laboratorio o da altezza superiori. Viene scelto principalmente per il suo grado di trasparenza.

Polietilene (PE):

materiale termoplastico composto da polimeri di etilene.

La polimerizzazione dell'etilene da luogo essenzialmente alla formazione di un idrocarburo ad alto peso molecolare a catena lineare.

Non esistono sostanze capaci di scioglier a temperatura ambiente il PE; solventi particolarmente aggressivi possono causare rammollimento o rigonfiamento, effetti che sono normalmente reversibili.

La resina viene ottenuta ad elevate temperature e pressioni in presenza di catalizzatori. In campo medicale viene usato nella produzione di tappi in genere e pipette Pasteur. E' deformabile al punto giusto per una tenuta ermetica ottimale del contenitore.

Le provette sterili con tappo a vite sono indicate in genere per la raccolta di aspirati tracheali, bronchiali, brushing, CSF o CNS. I materiali utilizzati per la produzione di queste provette sono quelli sopra indicati.

Anche in questo caso in commercio vi è una vasta scelta: coniche, a fondo rotondo, a fondo rotondo con supporto esterno di appoggio sul piano di lavoro, graduate e non.

Sono contenitori monouso, a volte in confezione singola; la sterilità è dichiarata dal produttore con certificato allegato dove è stabilita la data di scadenza e il metodo utilizzato.

Prima dell'uso di contenitori e/o provette è necessaria un'ispezione visiva per accertarne l'integrità.

I campioni vengono raccolti secondo le modalità specifiche per ogni ricerca od esame.

In generale si può dire che le procedure di raccolta dei campioni devono contemplare metodi e tecniche in grado di evitare una contaminazione del campione e le modalità di trasporto al laboratorio devono garantire l'integrità del contenitore stesso. Una verifica di integrità e perfetta chiusura del contenitore/provetta deve essere effettuata al ricevimento del campione. (vedi idoneità campioni).

\section{Contenitori e terreni per la raccolta e trasporto di materiale fecale}

Per la raccolta di materiale fecale le linee guida generali (tab.3) prevedono:

- per coprocoltura l'uso di contenitori sterili tappo a vite o sistema trasporto tampone con terreno Cary- Blair o soluzione gli cero salina tamponata (BGS). 
- per la ricerca parassitologica l'uso di contenitori specifici.

Per quanto riguarda i contenitori sterili tappo a vite vale quanto già detto nel capitolo precedente per tipologia di materiali, uso, sterilità e verifiche di integrità. Possiamo aggiungere che in commercio vi sono disponibili contenitori muniti di cucchiaio in polipropilene per la raccolta, fissato al tappo; o contenitori con coperchio munito di apertura per facilitare il prelievo del materiale raccolto. Si possono trovare anche contenitori sterili con tappo a pressione.

Il terreno di trasporto Cary-Blair come detto, è particolarmente indicato per il trasporto e ricerca di numerosi patogeni enterici, compresi Shigella, Vibrio cholerae e E.coli $\mathrm{O} 157: \mathrm{H} 7$.

Per il trasferimento del campione,che non può essere seminato entro il tempo previsto, utilizzare un tampone sterile in cotone o poliestere per prelevare una piccola quantità di feci, in particolare raccogliendo muco o frammenti di epitelio intestinali dove presenti, e inserirlo immediatamente nel terreno di trasporto.

I campioni in terreno di trasporto dovrebbero essere refrigerati fino al momento della semina.

Se i campioni devono essere conservati per più di 2 o 3 giorni è preferibile il congelamento immediato a $-70^{\circ} \mathrm{C}$.

E' possibile la ricerca di patogeni da campioni congelati fino a 7 giorni dalla raccolta, tuttavia la possibilità diminuisce già dopo $1 \mathrm{o} 2$ giorni.

La semina immediata, la refrigerazione o il congelamento dei campioni nel terreno Cary-Blair è particolarmente importante per l'isolamento di Shigella, più fragile rispetto ad altri organismi enterici. (12)

\section{Contenitori e conservanti/fissativi per la ricerca di parassiti}

La qualità della fase preanalitica per la ricerca dei parassiti, al di là degli aspetti non trascurabili di sicurezza soprattutto per l'operatore, sarà garantita da un'adeguata raccolta del campione fecale (sia nei tempi che nei modi), da un adeguato numero di campioni fecali successivi, dall'idoneità degli eventuali conservanti utilizzati allo scopo. Al paziente devono essere fornite indicazioni precise sulla modalità di raccolta.

Il materiale fecale viene raccolto negli appositi contenitori con tappo a vite e inviati quanto prima possibile al laboratorio(conservandoli nel frattempo in frigorifero).

Nel caso in cui non fosse possibile far pervenire rapidamente (entro 6-12 ore) il campione in laboratorio, un'alternativa può essere quella di porre le feci in flaconi (anche più di uno e diversificati) contenenti sostanze conservanti quali formalina al $10 \%$, SAF, PVA, MIF, la cui scelta è in funzione del tipo di indagine che verrà svolta. In caso di feci liquide (in presenza di diarrea acuta o protratta) il campione va inviato entro 30 minuti dall'emissione ed esaminato subito. Per alcuni tipi di indagine non è possibile l'uso dei conservanti.

Per la conservazione dei campioni fecali in linea di massima le indicazioni sono:

- campioni liquidi: devono essere esaminati e/o conservati entro 30 minuti dall'emissione

- campioni soffici (non formati): devono essere esaminati e/o conservati entro 1 ora dall'emissione

- campioni formati: devono essere esaminati e/o conservati entro 12 ore dall'emissione

Qualunque sia il tipo di conservante utilizzato, è obbligatoria una perfetta omogeneizzazione al momento del contatto fra conservante e campione di feci.

Il "goal" per una perfetta conservazione dei parassiti, e per una buona qualità nelle colorazioni permanenti (per i protozoi), dipende fondamentalmente da questa prima fase.

La miscelazione del campione con fissativi effettuata quando questo giunge in laboratorio, non produce alcun miglioramento se non vengono rispettati i tempi sopra indicati; i risultati delle ricerche di trofozoiti (colorazioni e colture) saranno deludenti e sarà inutile ricercane le cause nelle metodiche o nei reattivi utilizzati.

Il campione deve essere fissato in questo modo: 1 parte di feci e 3 parti di fissativo. Un rapporto inferiore solitamente non permette una corretta fissazione dei parassiti.

Le cisti di protozoi si fissano in genere meno bene dei trofozoiti in quanto il fissativo deve penetrare nella parete cistica; è quindi importante, si ripete, che il campione venga perfettamente miscelato con il fissativo.

Per problemi di sicurezza (i fissativi possono essere tossici, irritanti ecc.) è preferibile miscelare il campione al fissativo in laboratorio.

Esistono in commercio dispositivi vari di raccolta del materiale fecale con conservante già inserito in opportune quantità.

Sono generalmente dispositivi standardizzati per la raccolta, trasporto, fissazione e filtrazione del materiale fecale. Se consegnato al paziente, è bene allegare indicazioni scritte con le precauzioni d'uso. (13)(15)

\section{Conservanti}

- Questi sono rappresentati da:

- Formalina al 5\% o al 10\%

- SAF (sodio acetato, acido acetico,formaldeide) 
- PVA (polivinilalcool, soluzione di Shaudinn)

- MIF (mertiolato,iodio, formalina)

\section{Formalina}

Sono raccomandate preferibilmente due tipi di preparazioni:

- soluzione al $5 \%$ in acqua o soluzione fisiologica per la conservazione di cisti e di trofozoiti di protozoi;

- soluzione al $10 \%$ in acqua $\circ$ in soluzione fisiologica per la conservazione di larve e uova di elminti;

nel caso non si disponesse di entrambe le soluzione, utilizzare formalina al $10 \%$.

Sui campioni fissati in formalina non è possibile eseguire le colorazioni permanenti per trofozoiti e cisti di protozoi (Giemsa, Field, Tricromia e con Ematossilina ferrica) né gli esami colturali per parassiti;

\section{SAF}

Questo conservante è poco corrosivo e non contiene composti a base di mercurio. E' meno costoso, relativamente più stabile. E' il fissativo che permette di ottenere i migliori risultati con la colorazione con Ematossilina ferrica.

Sui campioni così conservati è possibile eseguire la concentrazione formalina-etere/etilacetato, la colorazione Tricromia(discreti risultati), la colorazione di Ziehl-Neelsen modificata (buoni risultati), la colorazione con fluorocromi, nonché la ricerca di antigeni fecali protozoari.

\section{PVA}

L'alcool polivinilico è una resina plastica che viene aggiunta al fissativo di Schaudinn (a base di mercurio) e provvede all'adesione del materiale al vetrino. La fissazione dei parassiti è così dovuta alla presenza del fissativo di Schaudinn.La stabilità di tale fissativo in piccoli contenitori è più ridotta rispetto al SAF ed è di circa 12 mesi. Si ottengono ottimi risultati con la colorazione tricromica, meno buoni con la Ematossilina ferrica. Non è possibile la ricerca di antigeni fecali protozoari.

Sono infine sconsigliati i metodi di concentrazione.

\section{MIF}

Questo conservante è di facile preparazione (quando non è già pronto all'uso) e non contiene composti a base di mercurio.
Permette l'esecuzione dell'esame diretto e della concentrazione con formalina-etere/etilacetato, ma non è idoneo per le colorazioni permanenti e per le colorazioni estemporanee per coccidi.

\section{Contenitori e trasporto di campioni per ricerche micologiche}

Fra le tappe più importanti per il successo nell'isolamento di agenti eziologici responsabili di micosi vi è il trasporto dei campioni che, secondo le linee guida, deve essere rapido, entro le due ore dalla raccolta, e seguito da un pronta e corretta processazione.

La vitalità può diminuire nei campioni conservati più a lungo.

I campioni vanno trasportati in contenitori sterili, in ambiente umidificato.

Solo per campioni dermatologici utilizzare un contenitore a secco.

Non usare terreno di trasporto a meno che il campione non possa essere facilmente e completamente inserito nel terreno.

L'uso di tamponi per raccolta e trasporto non è consigliato, tuttavia vi sono alcuni siti corporei come il canale auricolare, la zona nasofaringea, quella vaginale e cervicale dove non sono utilizzabili altri mezzi.

Utilizzare in questi casi un terreno di trasporto per aerobi.

I capelli possono essere inseriti tra due vetrini puliti e trasportati con contenitore apposito.

L'effetto della refrigerazione sui campioni per ricerche micologiche non è ancora ben definito, ma se la processazione ritarda di parecchie ore, è bene conservare il campione a $4^{\circ} \mathrm{C}$ eccetto sangue e CSF che vanno conservati a $30-37^{\circ} \mathrm{C}$.

Campioni di tessuto possono essere conservati a $4^{\circ} \mathrm{C}$ per non più di otto ore aggiungendo una piccola quantità di soluzione fisiologica per evitare il fenomeno di essiccazione.

Campioni di urina (non delle 24 ore) possono essere conservati a $4{ }^{\circ} \mathrm{C}$ per $12-14$ ore.

Conservare i campioni dermatologici da 15 a $30^{\circ} \mathrm{C}$.

\section{Valutazione di idoneità}

\section{La fase preanalitica del campione} $\underline{\text { microbiologico si conclude con una valutazione }}$ di idoneità che comprende:

- appropriata identificazione del campione

- adeguatezza del campione

- appropriato contenitore o mezzo di trasporto

- verifica dei tempi di trasporto e consegna rispetto al tempo di raccolta del campione

Queste procedure consentono di avere la certezza 
che il campione è adeguato ed appropriato per la ricerca batteriologica.

Dalle linee guida possiamo riportare alcuni indicazioni generali per una fase di valutazione inserita nel percorso per la Qualità in Microbiologia. Tutti i contenitori devono essere identificati con il nome del paziente e/o con etichetta riportante il relativo codice a barre, e devono riportare indicazione del materiale e/o indagine richiesta.

Ogni contenitore deve essere accompagnato da apposito modulo di richiesta (dove non è attiva una via informatica di accettazione) correttamente e completamente compilata.

Il campione deve essere inviato tempestivamente e, comunque nel rispetto delle indicazioni di conservazione indicate per ciascuna indagine e/o campione.

\section{Casi di inaccettabilità del campione}

- Contenitori non sterili

- Contenitore o mezzo di trasporto non idoneo al tipo di esame richiesto;

- Contenitori visibilmente danneggiati con fuoriuscita del materiale

- Contenitori o campioni non identificati o non correttamente identificati; nel caso di campione non accettabile è necessario procedere ad una notifica telefonica e scritta con motivazione del rifiuto e richiesta di invio di altro campione (nei casi possibili); documentare se nel frattempo il paziente ha intrapreso terapia antibiotica o se l'invio di altro campione non è possibile

- Contenitore/campione e richiesta non concordanti nell'identificazione paziente

- Campioni doppi: nella maggior parte dei casi non vanno processati più campioni dello stesso tipo, stesso paziente, nella stessa data. Fanno eccezione emocolture, CSF, tessuti, fluidi sterili escluse le urine.

- Contenitori contaminati: il campione è inaccettabile se il contenitore è macroscopicamente contaminato esternamente tranne il caso in cui il recupero del materiale sia possibile senza contaminazione per l'operatore;

- Materiali contaminati con altri materiali come ad esempio:

urine con feci e viceversa;

espettorato con massiccia presenza di saliva; (nota: l'espettorato indotto può contenere piccole quantità di soluzione salina apparentemente scambiabili per saliva, in questo caso selezionare la porzione del materiale più densa.)

- Materiale non idoneo per la ricerca richiesta come ad esempio:

raccolta urine 24 ore per urinocoltura

raccolta urine 24 ore, o da catetere o quantità
$<$ a $40 \mathrm{ml}$ per ricerca micobatteri; (14)

sangue coagulato

sangue raccolto con EDTA per ricerca micobatteri (inibisce la crescita anche se presente in piccole quantità) (14)

campioni di tessuto (biopsie, linfonodi) vari in formalina per ricerca micobatteri (14)

- Tamponi a secco o tamponi con ampolla integra (L'ampolla deve essere rotta al momento dell'inserimento del tampone nel terreno)

- Tempo di trasporto prolungato.

Per ogni ricerca e tipologia di mezzo di trasporto utilizzato devono essere rispettati i tempi di trasporto e la conservazione del materiale per esempio:

- urine e campioni del tratto respiratorio devono pervenire entro 1 ora dalla raccolta a meno che non siano refrigerati; deve esserci evidenza di refrigerazione del campione; i campioni di urina devono essere processati entro $2-8$ ore se refrigerati, non conservare oltre le 24 ore.

- campioni fecali devono essere stati raccolti da non più di 1 ora o devono essere ricevuti in terreno di trasporto (Cary-Blair e BGS); se è trascorsa più di 1 ora dalla raccolta porre il materiale fecale in terreno di trasporto immediatamente prima di richiedere un altro campione. L'invio di altro materiale può essere difficoltoso $\mathrm{o}$ il paziente può già aver intrapreso terapia antibiotica.

- campioni di fluidi sterili o materiale da ferite raccolti in trasporto per anaerobi devono pervenire il prima possibile, se raccolti in altri contenitori devono essere inviati entro 1 ora.

- piastre di T.Martin o altri terreni di trasporto per N.gonorrhoeae devono essere state inoculate da non più di mezz'ora.

Idealmente tutti gli altri campioni non devono essere stati raccolti da più di 2 ore; appropriati terreni di trasporto e istruzioni dettagliate devono essere disponibili per il trasporto dei campioni.

Se si processa un campione non appropriato è necessario specificarlo sul report ed aggiungere un commento, ad esempio: i microrganismi isolati possono non riflettere l'attuale microbiota a causa di procedura di raccolta/ trasporto/ conservazione non corretta..

Ogni laboratorio di microbiologia dovrebbe avere un protocollo definito per la rilevazione delle non conformità e la non accettabilità dei campioni predisponendo misure di comportamento specifiche. 
Mezzi di trasporto del campione biologico: contenitori e terreni (una valutazione di idoneità) Graziella Marin TSLB - Laboratorio Patologia Clinica Ospedale S.Maria del Carmine Rovereto (TN)

\section{SCHEMI RIASSUNTIVI}

\section{IL TAMPONE}

Un sistema di raccolta e trasporto comune a molti campioni è il tampone (SWAB), in fibre diverse e supporti diversi. Attualmente i tamponi batteriologici sono costituiti da bacchette di supporto in materiale plastico, legno o filo metallico con all'estremità delle fibre assorbenti:

$\square$ Naturali: cotone

Sintetiche: nylon, dacron, rayon, calcio arginato A volte impregnate con carbone, siero o frazioni di albumina

\section{IL TAMPONE: LE FIBRE}

L'uso di una fibra piuttosto che un'altra è elemento di criticità nella fase preanalitica.

$\square$ cotone: può contenere acidi grassi tossici per determinati organismi

$\square$ calcio arginato: non dovrebbe essere usato per quei campioni dove sono necessari reagenti di estrazione o per ricerche virali o ricerca Chlamydia

$\square$ dacron e rayon: sono da considerarsi fibre ideali

\footnotetext{
IL TAMPONE:VITALITÀ E SOPRAVVIVENZA DEI MICRORGANISMI

La scelta del tampone deve basarsi sulla conoscenza della correlazione esistente tra tipo di fibra e tipologia di materiale o ricerca da effettuare.

Ad es. per la Neisseria gonorrhoeae:

$\square$ tamponi in calcio alginato: risultano tossici

$\square$ tamponi in rayon e cotone: garantiscono la sopravvivenza circa $6 \mathrm{~h}$

$\square$ i risultati migliorano con l'uso di tamponi abbinati a terreno di trasporto, (Amies con carbone) indipendentemente dal tipo di fibra

In generale la sopravvivenza dei microrganismi:

con i tamponi a secco varia da $20 \%$ a zero, dopo 4 ore dal prelievo

$\square$ con i sistemi di trasporto permane fino a $24-48$ ore dal prelievo
}

\section{IL TAMPONE: USO}

$\square$ tamponi in cotone grezzo a secco devono essere utilizzati solamente quando è possibile eseguire la coltura subito dopo la raccolta del materiale $\square$ tamponi a secco con carbone, con albumina o calcio-alginato, quando le colture si possono eseguire entro le 4 ore

Per periodi di tempo maggiori devono essere utilizzati solo sistemi con terreno di trasporto

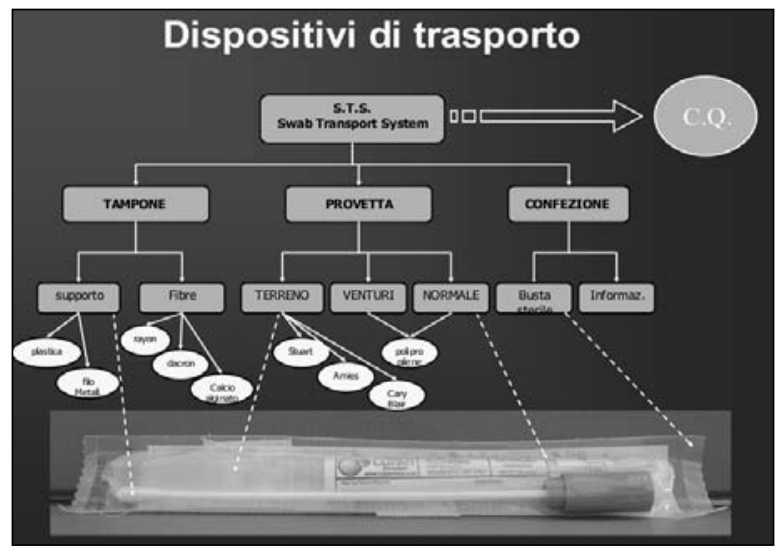

II terreno di trasporto: quale funzione? I microrganismi patogeni muoiono facilmente in ambiente secco e alcuni sono sensibili alla concentrazione di ossigeno atmosferico. I terreni di trasporto sono stati creati per proteggere $i$ batteri da:

$\square$ Essiccazione $\square$ Acidi grassi tossici $\square \mathrm{pH}$ sfavorevole $\checkmark$ Effetti letali dell'ossigeno atmosferico

I terreni di trasporto sono formulati per mantenere la vitalità batterica senza incrementarne la crescita e la moltiplicazione.

Per la raccolta e conservazione dei campioni batteriologici i più usati sono:

$\square$ Terreno di Stuart $\square$ Terreno di Amies $\square$ Terreno Cary-Blair

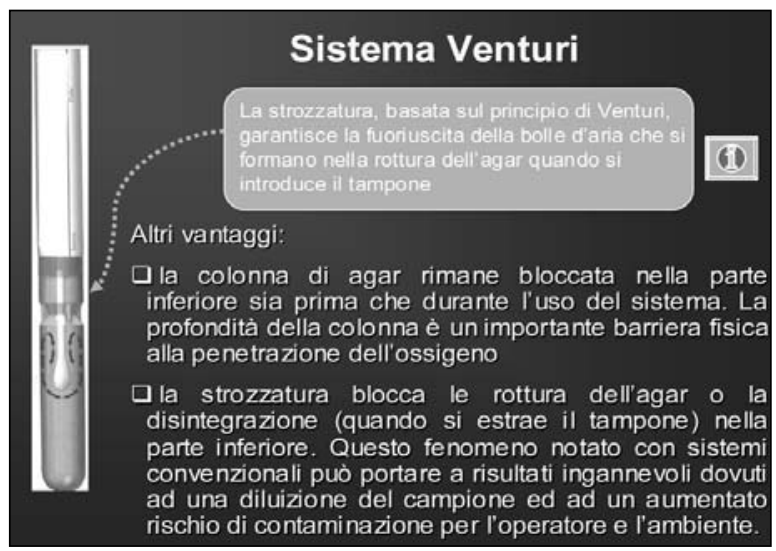

\section{Dispositivi di trasporto tampone: Controllo di Qualità}

$\square$ Le linee guida generali prevedono un CQ per i terreni di trasporto con ceppi ATCC.

In genere sono riportati:

\section{Dispositivi di trasporto tampone: Certificati di Qualità}

$\square$ test per la sterilità $\square$ test per la carica batterica non vitale $\square$ test di parametri fisico/chimici $\square$ test di performance con ceppi ATCC e risultati ottenuti

$\square$ scadenza, numero lotto,modo d'uso e conservazione $\square$ metodo di sterilizzazione per il prodotto finale

II laboratorio deve conservare copia dei certificati di qualità, rilevando le eventuali non conformità 


\section{Dispositivi di trasporto tampone: valutazioni della performance}

Organismi chiave per la valutazione sono batteri anaerobi ed aerobi (difficili o sensibili) quali H.influenzae, S.pneumoniae, S.pyogenes, N.gonorrhoeae (ceppi ATCC)

Fattori che influenzano la capacità di ritrovamento dei batteri:

$\square$ INTRINSECl: contenitore, terreno, tipo di tampone;

$\square$ ESTERNI: temperatura di conservazione, tempo di conservazione, modalità di semina

- VARIABILI INCONTROLLABILI: viscosità dei campioni clinici, presenza di cellule e componenti chimici (possono agire da nutrienti o essere tossici e quindi influenzare la vitalità batterica), eventuale presenza di sangue/materiale purulento influenza la sopravvivenza perché contrasta il fenomeno di essiccamento e l'effetto dannoso dell'esposizione all'aria.

\section{Dispositivi di trasporto tampone: la temperatura di conservazione}

Sorprendenti sono i risultati di un lavoro pubblicato nel maggio 2001 ,(8), dove si valutano gli effetti protettivi di vari dispositivi di trasporto fino a 72 ore conservati a temperatura ambiente e a $4^{\circ} \mathrm{C}$

$\square$ tamponi a secco: non mantengono la vitalità in nessun caso

$\square$ tamponi con terreno di trasporto: consentono la vitalità fino a $24 \mathrm{~h}$ a T.A.

$\square$ solo tamponi conservati a $4^{\circ} \mathrm{C}$ consentono di ritrovare organismi vitali dopo 48-72 $\mathrm{h}$

Le storiche disposizioni per il trasporto/conservazioni dei campioni possono non riflettere accuratamente le capacità dei moderni dispositivi. Standardizzare i test di controllo di qualità e stabilire criteri di accettabilità diventerà importante per assicurare un più elevato livello di cura ai pazienti.

\section{ANNO 2002 - NCCLS NEWS}

NCCLS pubblica il documento M40-P: “Quality Control Standards of Microbiological Transport System; Proposed Standard" che comprende gli standard per valutare la performance dei dispositivi di trasporto con tampone e stabilisce i criteri di accettabilità.

$\square$ Dichiara che:...il controllo di qualità consiste in una valutazione delle caratteristiche di performance di un dispositivo completo e non dei componenti individuali...

$\square$ Riconosce che:...la temperatura ha un significativo effetto sulla conservazione dei microrganismi...

$\square$ Prevede che:... visti i risultati dei recenti studi sugli effetti della temperatura di conservazione, i produttori di dispositivi eseguano $\mathrm{CQ}$ sia a T.A. che a $4-8^{\circ} \mathrm{C}$ e riportino i risultati sui foglietti illustrativi interni del prodotto...

\section{Anno 2003 - LO STATO DELL'ARTE}

Il recente documento M40-P è lo "starting point" per il controllo di qualità dei dispositivi di trasporto.

Due lavori di valutazione, (pubblicati a maggio2003) (I0)(II) applicano i nuovi standard e supportano le affermazioni precedenti:

$\square$ La temperatura di conservazione di $4-8^{\circ} \mathrm{C}$ è chiaramente superiore nel garantire la sopravvivenza per tempi prolungati nella maggior parte degli organismi difficili

$\square$ Le raccomandazioni di mantenere i dispositivi di trasporto tampone a t.a. durante il trasporto, devono essere riviste all'evidenza dei dati riscontrati.
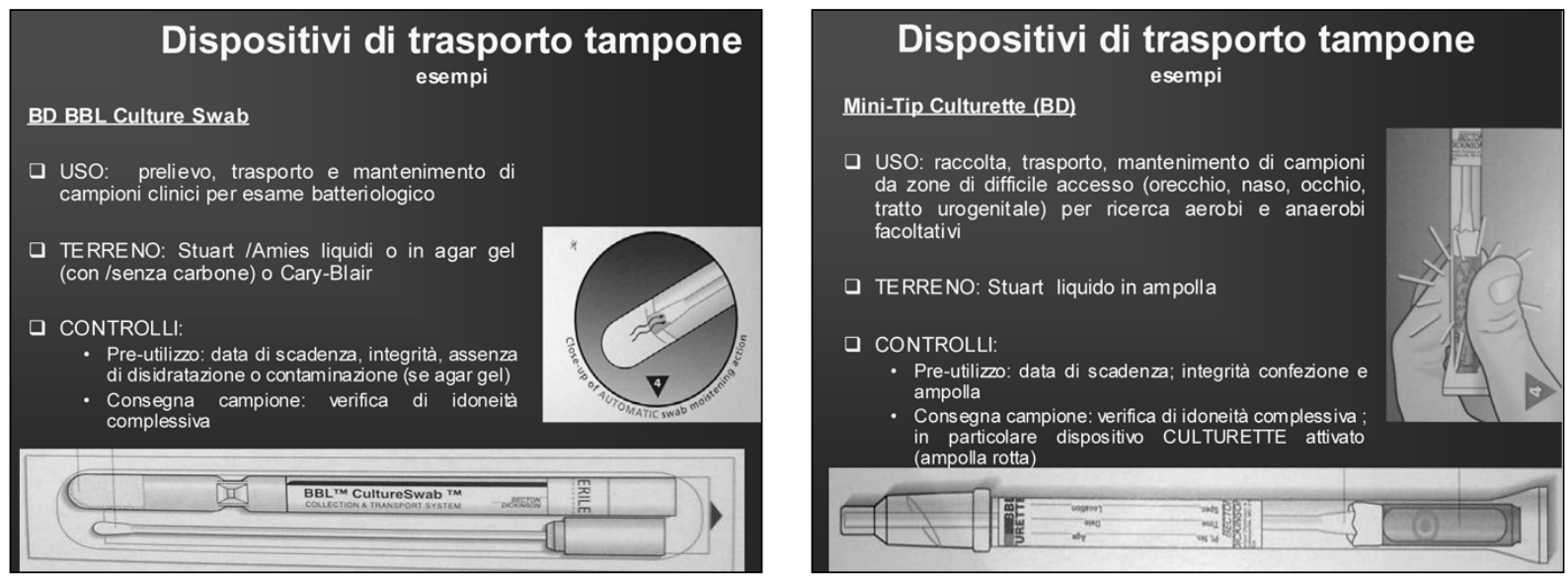

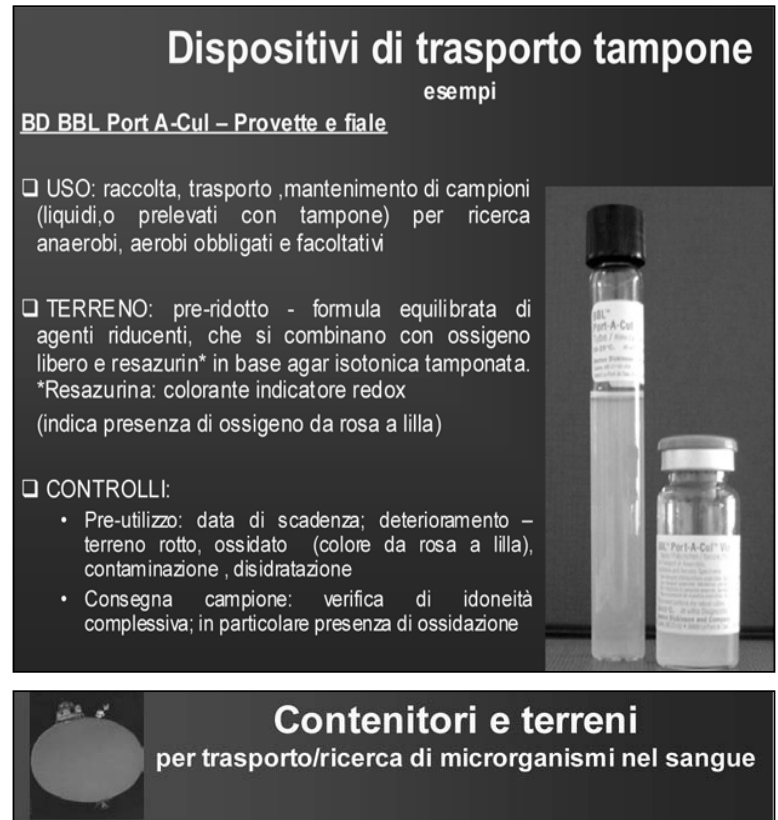

Le linee guida generali descrivono vari terreni e tecniche di coltura del sangue. I terreni non svolgono solo la funzione di trasporto ma contengono anche tutti i principi nutritivi necessari allo sviluppo dei microrganismi eventualmente presenti.

\section{In commercio sono disponibili :}

$\square$ Contenitori e terreni per sistemi automatici

- Contenitori e terreni per emocolture manuali (sistema bifasico)

$\square$ Dispositivo di lisi-centrifugazione (ISOLATOR) per inoculo nei terren specifici

CONSIDERAZIONI GENERALI

口II rapporto sangue-terreno raccomandato è da $1: 3$ a $1: 10$

$\square$ ॥ terreno di coltura dovrebbe contenere SPS (polyanetholesulfonate) (11)
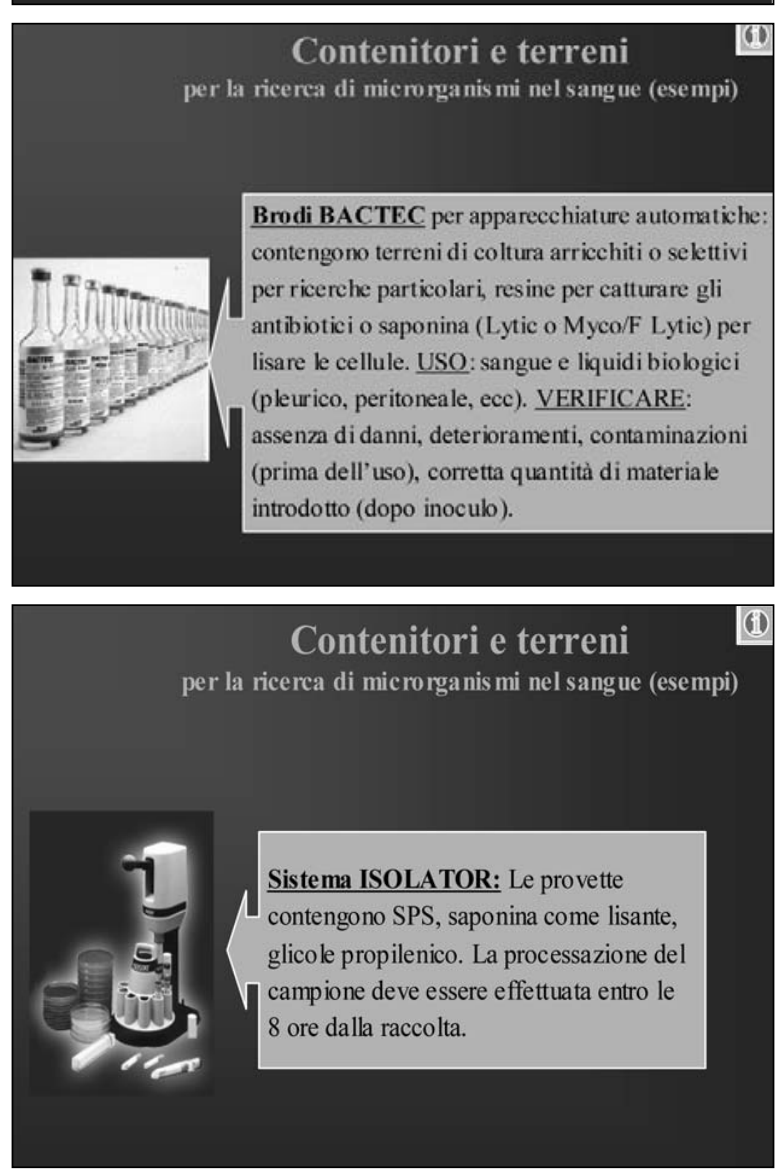

\section{Terreni di trasporto}

per ricerche particolari (esempio)

Mycofast Evolution 2

U USO: ricerca micoplasmi urogenitali.

- TERRENO: liquido, pronto all'uso,

contiene beta-lattamici e sulfamide per inibire la crescita batterica.

口 CONTROLLI:

- Pre-utilizzo: data di scadenza, contaminazione

- Consegna campione: dopo inoculo si può conservare a T.A $\left(18-25^{\circ} \mathrm{C}\right)$ per 8 ore $\circ$ a $2-8^{\circ} \mathrm{C}$ per 36 ore

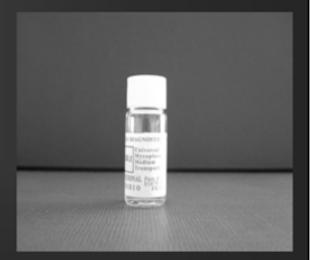

\section{Contenitori e terreni}

per la ricerca di microrganis mi nel sangue

SPS (polyanetholesulfonate) anticoagulante che:

$\square$ inibisce l'attività battericida del siero verso molti batteri patogeni,

$\square$ inibisce la fagocitosi,

$\square$ inattiva il complemento,

$\square$ neutralizza i lisozimi e la classe degli aminoglicosidi degli antimicroobici

in concentrazione da 0.025 a $0.5 \%$ :
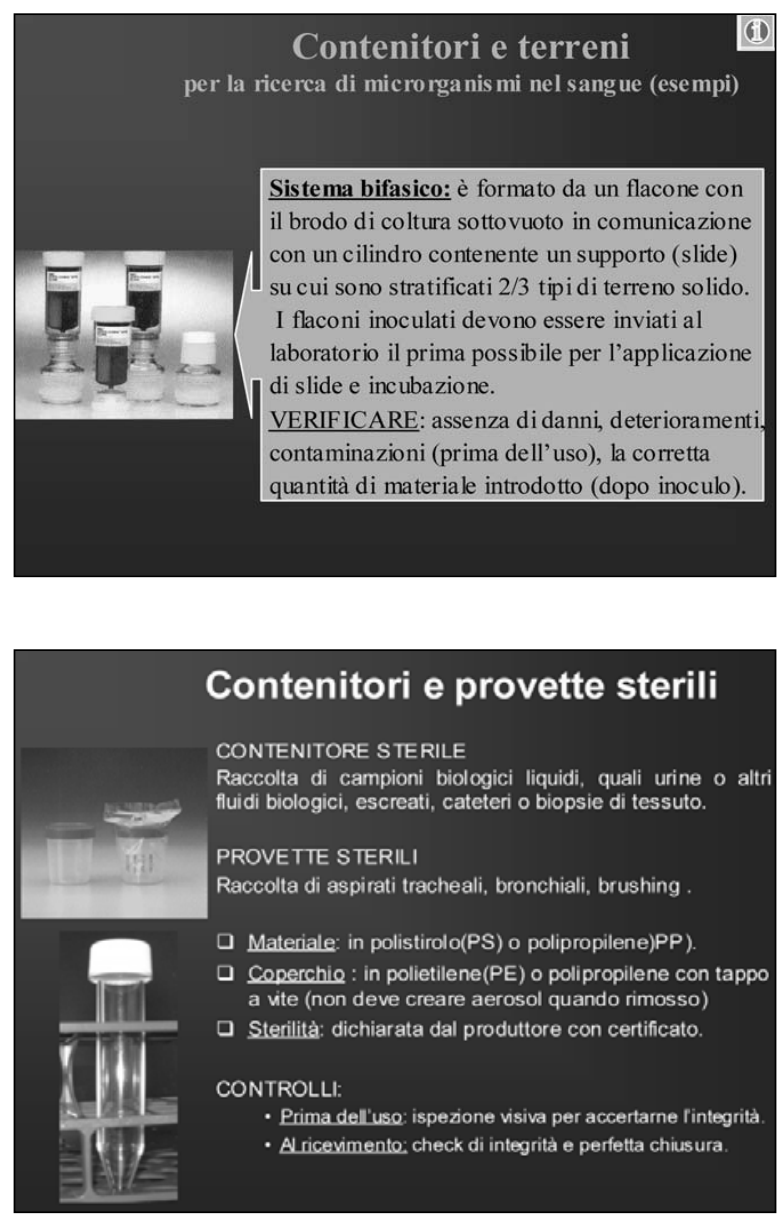

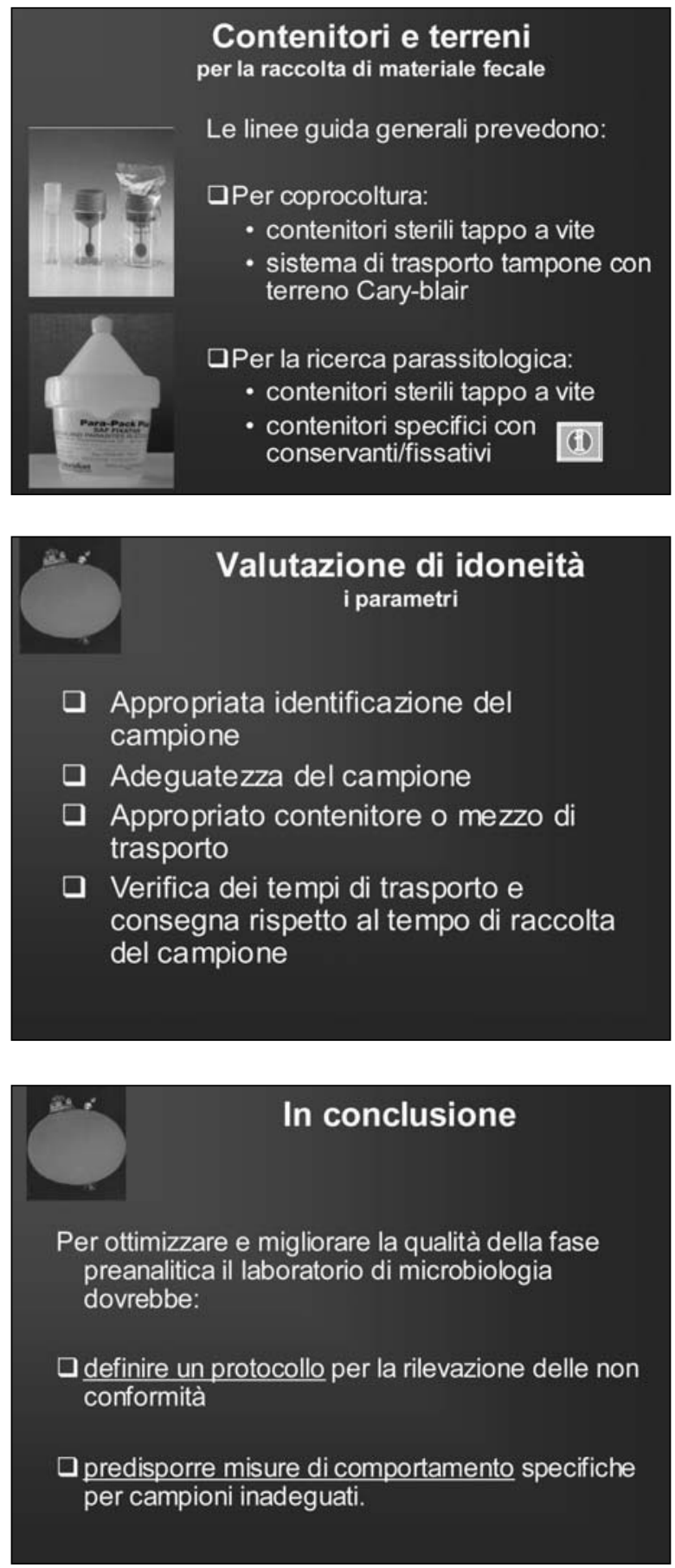

Mezzi di trasporto: contenitori e terreni per esami da eseguire nei settori di immunologia umorale, immunologia cellulare, virologia diretta e biologia molecolare.

\section{INTRODUZIONE}

Tutta la serie di operazioni, dal momento del prelievo del campione diagnostico al momento dell'esecuzione dell'esame di laboratorio, atta a conservare al meglio sia in qualità che in quantità gli analiti che andiamo ricercare, può essere definita: preanalitica conservativa.
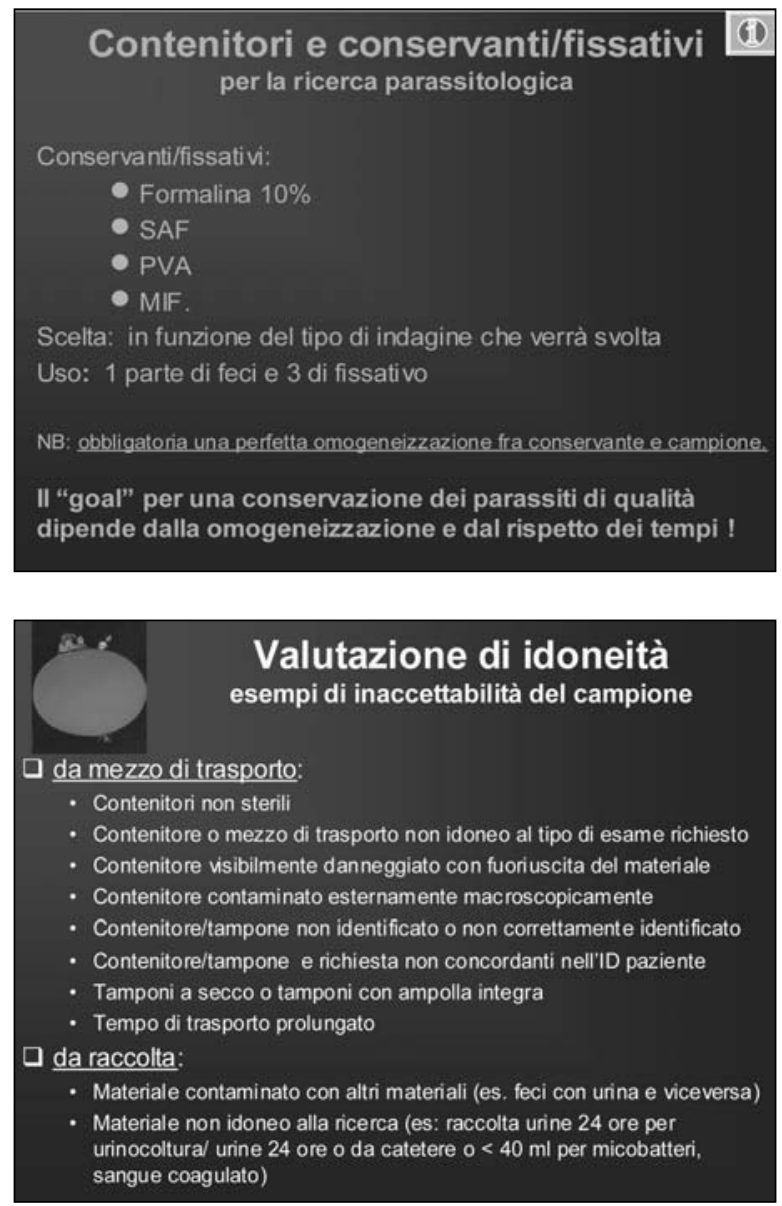

Quali sono i protocolli da seguire per ottenere il massimo della conservazione?

Dipende da ciò che si deve rilevare e dalle sue caratteristiche intrinseche di conservazione e dal metodo diagnostico utilizzato.

Infatti, se ricerchiamo la presenza di un virus in un campione mediante un metodo immunoenzimatico, ci basta avere in ottimo stato conservativo gli epitomi antigenici specifici, mentre se si deve effettuare una coltura virale allora è di fondamentale importanza che il virus sia vivo.

Elemento fondamentale comune a tutti gli esami di laboratorio con cui abbiamo a che fare è il contenitore.

$\mathrm{Ci}$ sono delle norme internazionali che regolamentano l'uso dei contenitori in laboratorio.

I materiali per eccellenza in uso attualmente sono il polipropilene e il polistirene.

\section{Preanalitica in IMMUNOLOGIA UMORALE}

L'immunologia umorale è quel settore della Microbiologia che studia la presenza di anticorpi e/o di antigeni in un soggetto.

Si opera su campioni di sangue,talvolta può essere usato il plasma (conservato in EDTA, ACD, eparina di sodio e citrato di sodio),ma più diffusamente viene usato il siero. 
Il prelievo di siero può essere effettuato in provette contenenti granuli di polistirene o gel, per la migliore separazione della fase corpuscolata da quella sierica.

In genere il gel viene usato per tutte le analisi escluse quelle che comportano l'incubazione del siero a $56^{\circ} \mathrm{C}$, quali la fissazione del complemento.

Infatti durante la centrifugazione, il gel, dalla sua posizione iniziale,ovvero nella parte inferiore della provetta, si porta alla posizione di separazione del coagulo, ed in questa fase possono essere rilasciate delle minime frazioni di sostanza gelatinosa, che con la scomplementazione a $56^{\circ} \mathrm{C}$ vanno ad interferire con i legami $\mathrm{Ag}-\mathrm{Ab}$, generalmente portando ad una sottostima dei valori analizzati.

Il sangue è composto da molti elementi e questi possono interferire con il risultato dell'analisi.

Un lavoro di Grafmeyer su esami di chimica clinica,effettuato su 20 tipi differenti di tests con 15 macchine differenti, ha rivelato una interferenza del seguente tipo: emolisi $34,5 \%$ su trigliceridi e proteine totali, bilirubina 21,7 su bilirubina e proteine totali, torbidità inferiore al $17 \%$ per acido ureico e proteine totali.

Poiche gli anticorpi sono proteine è ovvio che questi tre elementi possono influenzarne la determinazione.
Per quanto riguarda la presenza di emolisi, l'ospedale di Padova ha messo on-line una tabella di valori ove si consiglia o sconsiglia l'accettazione del campione ematico: in presenza di una concentrazione di 0,5 gr/L di emoglobina su siero, l'esame viene eseguito, se la concentrazione è di $1 \mathrm{gr} / \mathrm{L}$ l'esame viene eseguito, ma la refertazione viene accompagnata da commento, se i valori sono superiori il campione viene scartato.

Per ovviare alla presenza di siero lipemico, i prelievi vengono tutti svolti previo digiuno di 8-12 ore.

Esistono d'altro canto delle patologie che prevedono delle terapie che possono portare ad avere un siero lipemico, in tal caso l'esame viene eseguito comunque, ma il risultato deve essere accompagnato da un commento.

Se l'esame non può essere eseguito subito, qual'è il comportamento da seguire?

Innanzitutto è necessario conoscere le caratteristiche degli analiti da rilevare e i fattori che influenzano la conservazione degli analiti a temperatura ambiente e a $4^{\circ} \mathrm{C}$.

Ad esempio l'inquinamento da batteri e miceti, può interferire pesantemente nelle determinazioni ed è frequente in caso di conservazione non corretta.

Infatti l'Isenberg, nel suo manuale, il Clinical Microbiology Procedures Handbook $(1,2)$, dà le

Tabella 5. Indicazioni per la conservazione dei campioni da analizzare con strumentazione Liaison (Diasorin)

\begin{tabular}{|c|c|c|c|c|c|c|}
\hline ESAME & $\begin{array}{c}\text { EMOLITICO } \\
\text { LIPEMICO } \\
\text { INQUINATO }\end{array}$ & $\begin{array}{l}\text { QUANDO } \\
\text { SIERARE }\end{array}$ & $\begin{array}{l}\text { Conservazione } \\
2^{\circ} \mathrm{C}-8^{\circ} \mathrm{C}\end{array}$ & $\begin{array}{l}\text { Conservazione } \\
-20^{\circ} \mathrm{C}\end{array}$ & $\begin{array}{l}\text { CICLI DI } \\
\text { CONG E } \\
\text { SCONG }\end{array}$ & NOTE \\
\hline $\begin{array}{l}\text { ROSOLIA } \\
\text { IgG }\end{array}$ & no & $\begin{array}{l}\text { Quanto } \\
\text { prima }\end{array}$ & $7 \mathrm{gg}$ & $\begin{array}{l}\text { Molti } \\
\text { Mesi }\end{array}$ & 3 & \\
\hline $\begin{array}{l}\text { ROSOLIA } \\
\text { IgM }\end{array}$ & no & $\begin{array}{l}\text { Quanto } \\
\text { prima }\end{array}$ & $7 \mathrm{gg}$ & $\begin{array}{l}\text { Molti } \\
\text { Mesi }\end{array}$ & 5 & \\
\hline $\begin{array}{l}\text { TOXO } \\
\text { IgG }\end{array}$ & no & $\begin{array}{l}\text { Quanto } \\
\text { prima }\end{array}$ & $7 \mathrm{gg}$ & $\begin{array}{l}\text { Molti } \\
\text { Mesi }\end{array}$ & 4 & \\
\hline $\begin{array}{c}\text { TOXO } \\
\text { IgM }\end{array}$ & no & $\begin{array}{l}\text { Quanto } \\
\text { prima }\end{array}$ & $7 \mathrm{gg}$ & $\begin{array}{l}\text { Molti } \\
\text { Mesi }\end{array}$ & 4 & \\
\hline $\begin{array}{c}\text { TOXO } \\
\text { IgG AV }\end{array}$ & no & $\begin{array}{l}\text { Quanto } \\
\text { prima }\end{array}$ & $7 \mathrm{gg}$ & $\begin{array}{l}\text { Molti } \\
\text { Mesi }\end{array}$ & 4 & \\
\hline $\begin{array}{l}\text { CMV } \\
\text { IgG }\end{array}$ & no & $\begin{array}{l}\text { Quanto } \\
\text { prima }\end{array}$ & $7 \mathrm{gg}$ & $\begin{array}{l}\text { Molti } \\
\text { Mesi }\end{array}$ & 6 & \\
\hline $\begin{array}{l}\text { CMV } \\
\text { IgM }\end{array}$ & no & $\begin{array}{l}\text { Quanto } \\
\text { prima }\end{array}$ & $7 \mathrm{gg}$ & $\begin{array}{l}\text { Molti } \\
\text { Mesi }\end{array}$ & 6 & \\
\hline $\begin{array}{c}\text { CMV } \\
\operatorname{IgG} \quad \mathrm{AV}\end{array}$ & no & $\begin{array}{l}\text { Quanto } \\
\text { prima }\end{array}$ & $7 \mathrm{gg}$ & $\begin{array}{l}\text { Molti } \\
\text { Mesi }\end{array}$ & 4 & \\
\hline
\end{tabular}


seguenti indicazioni:

\begin{tabular}{ll}
\hline $\mathrm{Ab}$ anti $\mathrm{HSV}, \mathrm{CMV}, \mathrm{VZV}$ & $2-8^{\circ} \mathrm{C} \times 7 \mathrm{gg}-20^{\circ} \mathrm{C}$ \\
\hline $\mathrm{Ab}$ anti EPSTEIN BARR & $2-8^{\circ} \mathrm{C} \times 7 \mathrm{gg}-20^{\circ} \mathrm{C}$ \\
\hline $\mathrm{Ab}$ anti $\mathrm{HAV}$ & $2-8^{\circ} \mathrm{C} \times 5 g g-20^{\circ} \mathrm{C}$ \\
\hline $\mathrm{Ab}$ anti $\mathrm{HBeAg}$, anti $\mathrm{HBsAg}$, & \\
anti $\mathrm{HBcAg}, \mathrm{HBsAg}$ & $2-8^{\circ} \mathrm{C} \times 5 g g-20^{\circ} \mathrm{C}$ \\
\hline $\mathrm{Ab}$ anti $\mathrm{HCV}$ & $2-8^{\circ} \mathrm{C} \times 5 g g-20^{\circ} \mathrm{C}$ \\
\hline $\mathrm{Ab}$ anti TOXO & $2-8^{\circ} \mathrm{C} \times 3 g g-20^{\circ} \mathrm{C}$ \\
\hline $\mathrm{Ab}$ anti BORRELIA & $2-8^{\circ} \mathrm{C} \times 7 g g-20^{\circ} \mathrm{C}$ \\
\hline $\mathrm{Ab}$ anti MYCOPLASMA & $2-8^{\circ} \mathrm{C} \times 3 g g-20^{\circ} \mathrm{C}$ \\
\hline $\mathrm{Ab}$ anti ASPERGILLUS & \\
e anti CANDIDA & $2-8^{\circ} \mathrm{C} \times 3 g g-20^{\circ} \mathrm{C}$ \\
\hline
\end{tabular}

Nel nostro laboratorio sono stati testati 3 campio- ni differenti per ricerca IgG e IgM Anti Toxoplasma, anti Rosolia e anti CMV.

L'esame e' stato eseguito su apparecchiatura Liaison (Diasorin) immediatamente dopo l'arrivo dei campioni e dopo aver lasciato il siero a contatto con il coagulo a T.A. per $7 \mathrm{gg}$.

I risultati sono perfettamente sovrapponibili,per cui, in realtà,le condizioni prudenziali suggerite da Isenberg ci danno la garanzia di operare correttamente.

Generalmente le condizioni di conservazione dei campioni sono sempre segnalate dai produttori dei kits.

In tabella 5 e 6 sono riportate le indicazioni per campioni da analizzare con strumentazione Liaison (Diasorin) e Axsym (Abbott) rispettivamente.

Tabella 6. Indicazioni per la conservazione dei campioni da analizzare con strumentazione Axsym (Abbott)

\begin{tabular}{|c|c|c|c|c|c|c|}
\hline ESAME & $\begin{array}{l}\text { EMOLITICO } \\
\text { LIPEMICO } \\
\text { INQUINATO } \\
\text { BILIRUBINA }\end{array}$ & $\begin{array}{l}\text { QUANDO } \\
\text { SIERARE }\end{array}$ & $2^{\circ} \mathrm{C}-8^{\circ} \mathrm{C}$ & $-20^{\circ} \mathrm{C}$ & $\begin{array}{l}\text { CICLI DI } \\
\text { CONG E } \\
\text { SCONG }\end{array}$ & NOTE \\
\hline HIV $1-2$ & $\begin{array}{l}\text { non } \\
\text { lipemico e } \\
\text { inq }\end{array}$ & $\frac{\text { Subito e }}{\text { bene }}$ & $14 \mathrm{gg}$ & $\begin{array}{l}\text { Molti } \\
\text { Mesi }\end{array}$ & 6 & No pool \\
\hline $\mathrm{HCV}$ & $\begin{array}{l}\text { non } \\
\text { lipemico e } \\
\text { inq }\end{array}$ & $\frac{\text { Subito e }}{\text { bene }}$ & $14 \mathrm{gg}$ & $\begin{array}{l}\text { Molti } \\
\text { Mesi }\end{array}$ & 0 & $\begin{array}{c}\text { No pool e } \\
56^{\circ} \mathrm{C}\end{array}$ \\
\hline HBsAg & $\begin{array}{l}\text { non } \\
\text { lipemico e } \\
\text { inq }\end{array}$ & $\frac{\text { Subito e }}{\underline{\text { bene }}}$ & $14 \mathrm{gg}$ & $\begin{array}{l}\text { Molti } \\
\text { Mesi }\end{array}$ & 6 & No pool \\
\hline $\begin{array}{l}\text { Anti- } \\
\text { HBsAg }\end{array}$ & $\begin{array}{l}\text { non } \\
\text { lipemico e } \\
\text { inq }\end{array}$ & $\begin{array}{l}\text { Anche } \\
\text { dopo } 7 \mathrm{gg} \text { in } \\
\text { frigo }\end{array}$ & $7 \mathrm{gg}$ & $\begin{array}{l}\text { Molti } \\
\text { Mesi }\end{array}$ & 6 & No $56^{\circ} \mathrm{C}$ \\
\hline $\begin{array}{l}\text { Anti- } \\
\text { HBeAg }\end{array}$ & $\begin{array}{l}\text { non } \\
\text { lipemico e } \\
\text { inq }\end{array}$ & $\begin{array}{c}\text { Anche dopo } \\
14 \mathrm{gg} \text { in } \\
\text { frigo }\end{array}$ & $14 \mathrm{gg}$ & $\begin{array}{l}\text { Molti } \\
\text { Mesi }\end{array}$ & 6 & $\begin{array}{c}\text { No pool e } \\
56^{\circ} \mathrm{C}\end{array}$ \\
\hline HBeAg & $\begin{array}{l}\text { non } \\
\text { lipemico e } \\
\text { inq }\end{array}$ & $\frac{\text { Subito e }}{\text { bene }}$ & $7 \mathrm{gg}$ & $\begin{array}{l}\text { Molti } \\
\text { Mesi }\end{array}$ & 6 & $\begin{array}{c}\text { No pool e } \\
56^{\circ} \mathrm{C}\end{array}$ \\
\hline $\mathrm{HBcAg}$ & $\begin{array}{l}\text { non } \\
\text { lipemico e } \\
\text { inq }\end{array}$ & $\begin{array}{c}\text { Anche dopo } \\
14 \text { gg in } \\
\text { frigo }\end{array}$ & $14 \mathrm{gg}$ & $\begin{array}{l}\text { Molti } \\
\text { Mesi }\end{array}$ & 6 & $\begin{array}{c}\text { No pool e } \\
56^{\circ} \mathrm{C}\end{array}$ \\
\hline $\begin{array}{l}\text { Anti- } \\
\text { HBcAg } \\
\text { IgM }\end{array}$ & $\begin{array}{l}\text { non } \\
\text { lipemico e } \\
\text { inq }\end{array}$ & $\begin{array}{c}\text { Anche dopo } \\
14 \text { gg in } \\
\text { frigo }\end{array}$ & $14 \mathrm{gg}$ & $\begin{array}{l}\text { Molti } \\
\text { Mesi }\end{array}$ & 6 & $\begin{array}{c}\text { No pool e } \\
56^{\circ} \mathrm{C}\end{array}$ \\
\hline
\end{tabular}


Tabella 7. indicazioni per conservazione dei campioni da analizzare mediante fissazione del complemento e metodica immunologia per ricerca anticorpi anti Borrelia e anti Helycobacter

\begin{tabular}{|c|c|c|c|c|c|c|}
\hline ESAME & $\begin{array}{l}\text { EMOLITICO } \\
\text { LIPEMICO } \\
\text { INQUINATO } \\
\text { BILIRUBINA }\end{array}$ & $\begin{array}{l}\text { QUANDO } \\
\text { SIERARE }\end{array}$ & $2^{\circ} \mathrm{C}-8^{\circ} \mathrm{C}$ & $-20^{\circ} \mathrm{C}$ & $\begin{array}{l}\text { CICLI DI } \\
\text { CONG E } \\
\text { SCONG }\end{array}$ & NOTE \\
\hline $\begin{array}{l}\text { VIRUS } \\
\text { NEUROTROPI } \\
\text { PNEUMOTROPI } \\
\text { E ALTRI }\end{array}$ & & & $5 \mathrm{gg}$ & $\begin{array}{l}\text { Molti } \\
\text { Mesi }\end{array}$ & & $56^{\circ} \mathrm{C} 30^{\prime}$ \\
\hline $\begin{array}{l}\text { Anti } \\
\text { BORRELIA }\end{array}$ & INDIFFERENTE & & & $\begin{array}{l}\text { Molti } \\
\text { Mesi }\end{array}$ & & $56^{\circ} \mathrm{C} 30^{\prime}$ \\
\hline $\begin{array}{l}\text { Anti } \\
\text { HELYCO } \\
\text { BACTER }\end{array}$ & INDIFFERENTE & & & $\begin{array}{l}\text { Molti } \\
\text { Mesi }\end{array}$ & & $56^{\circ} \mathrm{C} 30^{\prime}$ \\
\hline
\end{tabular}

In alcuni casi,come evidenziato in tabella $n^{\circ} 7$, non sono disponibili indicazioni dettagliate, per cui il Clinical Microbiology Procedures Handbook è il riferimento più sicuro.

Tabella 8. Indicazioni per la conservazione dei campioni per la ricerca di lgE specifiche e autoanticorpi.

\begin{tabular}{|c|c|c|c|c|c|c|}
\hline ESAME & $\begin{array}{c}\text { EMOLITICO } \\
\text { INEUINATO } \\
\text { BILIRUBINA }\end{array}$ & $\begin{array}{c}\text { QUANDO } \\
\text { SIERARE }\end{array}$ & $\begin{array}{c}2^{\circ} \mathrm{C} \\
-8^{\circ} \mathrm{C}\end{array}$ & $-20^{\circ} \mathrm{C}$ & $\begin{array}{l}\text { CICLI } \\
\text { CONG } \\
\text { E } \\
\text { SCONG }\end{array}$ & NOTE \\
\hline $\begin{array}{c}\text { IgE } \\
\text { specifiche }\end{array}$ & NO & Quanto prima & $7 \mathrm{gg}$ & Molti Mesi & $\begin{array}{c}\text { Siero } \\
\text { e plasma }\end{array}$ \\
\hline $\begin{array}{c}\text { ANA } \\
\text { NOS }\end{array}$ & NO & Max 8 h T.A. & $2 \mathrm{gg}$ & Molti Mesi & Siero \\
\hline $\begin{array}{c}\text { ANCA } \\
\text { MPO-PR3) }\end{array}$ & NO & Max 8 h T.A. & $2 \mathrm{gg}$ & Molti Mesi & & $\begin{array}{c}\text { Siero } \\
\text { Siero e plasma }\end{array}$ \\
\hline $\begin{array}{c}\text { TPO-TG } \\
\text { tTG }\end{array}$ & NO & Quanto prima & $3 \mathrm{gg}$ & Molti Mesi & $\begin{array}{c}\text { Siero } \\
\text { e plasma }\end{array}$ \\
\hline aCL & NO & Quanto prima & $\begin{array}{c}\text { Siero } \\
\text { plasma }\end{array}$ \\
\hline TRAK & NO & Quanto prima & $3 \mathrm{gg}$ & Molti Mesi & & Siero \\
\hline GAD & NO & Quanto prima & $1 \mathrm{gg}$ & Molti Mesi & & Siero \\
\hline IA 2 & NO & Quanto prima & $1 \mathrm{gg}$ & Molti Mesi & & Siero \\
\hline
\end{tabular}




\section{Preanalitica in IMMUNOLOGIA CELLULARE}

L'immunologia cellulare è quel settore della Microbiologia che ricerca gli epitopi di superficie dei linfociti di classe A,B,C, DR e DQ .

Il campione di sangue deve essere raccolto ed in provetta con EDTA.

Essendo dimostrato che la raccolta linfocitaria dopo separazione su Ficoll è molto più ricca e ben conservata se effettuata entro le $24 \mathrm{~h}$ dal prelievo (Nicholson JK), la separazione dei linfociti va fatta entro tali termini.

Essendo l'HLA un esame basato sulla citotossici- tà, avere a monte le cellule in condizioni ottimali di conservazione, è essenziale per l'interpretazione del risultato.

\section{Preanalitica in VIROLOGIA DIRETTA}

I virus sono parassiti endocellulari obbligati,per cui per potersi replicare devono obbligatoriamente disporre di cellule vitali.

Alcuni virus sono inoltre così esigenti che ancor oggi per loro non si conoscono linee cellulari adeguate per farli replicare in vitro.

Sono comunque disponibili metodiche che evidenziano antigeni virali direttamente nel campio-

Tabella 9. modalità di conservazione dei campioni per ricerche virologiche dirette

\begin{tabular}{|c|c|c|c|c|c|c|}
\hline MATERIALE & CONSEGNA & $\begin{array}{l}\text { QUANDO } \\
\text { SEMINARE }\end{array}$ & $\begin{aligned} & { }^{\circ} \mathrm{C} \\
- & 8^{\circ} \mathrm{C}\end{aligned}$ & $-70^{\circ} \mathrm{C}$ & $\begin{array}{c}\text { CICLI } \\
\text { DI } \\
\text { CONG } \\
\text { E } \\
\text { SCONG }\end{array}$ & NOTE \\
\hline SANGUE x CMV & $\begin{array}{l}\text { Max 1h } \\
30 ”\end{array}$ & $\begin{array}{l}\text { Quanto } \\
\text { prima }\end{array}$ & & & & \\
\hline FECI & $\begin{array}{l}\operatorname{Max} 1 \mathrm{~h} \\
30 "\end{array}$ & Quanto prima & & Molti Mesi & & \\
\hline URINE & $\begin{array}{l}\text { Max } 1 \mathrm{~h} \\
30 ”\end{array}$ & Quanto prima & $7 \mathrm{gg}$ & Molti Mesi & & \\
\hline LIQUOR & $\begin{array}{l}\text { Max } 1 \mathrm{~h} \\
30 ”\end{array}$ & Quanto prima & & & & \\
\hline ESCREATO & $\begin{array}{l}\operatorname{Max} 1 \mathrm{~h} \\
30 "\end{array}$ & Quanto prima & & Molti Mesi & & \\
\hline $\begin{array}{l}\text { TAMPONI } \\
\text { PER VIRUS }\end{array}$ & $\begin{array}{l}\operatorname{Max} 1 \mathrm{~h} \\
30 "\end{array}$ & Quanto prima & & Molti Mesi & & \\
\hline $\begin{array}{l}\text { TAMPONI PER } \\
\text { CHLAMYDIAE }\end{array}$ & $\underset{30 ”}{\operatorname{Max} 1 \mathrm{~h}}$ & Quanto prima & & Molti Mesi & 1 & \\
\hline $\begin{array}{l}\text { VETRINI PER CHL. } \\
\text { PNEUMONIAE } \\
\text { CHL.TRACHOMATIS }\end{array}$ & & $\begin{array}{l}\text { Fissare in } \\
\text { acetone a t.a. } \\
\text { quanto prima }\end{array}$ & & Molti Mesi & & \\
\hline
\end{tabular}


ne (EIA,IF) ed in tal caso è sufficiente che l'assetto antigenico del virus sia ben conservato, non è indispensabile che sia vivo.

Quando è necessario invece, coltivare i virus presenti nei campioni biologici è di fondamentale importanza che i microrganismi siano vitali ed è pertanto essenziale creare le condizioni ottimali di sopravvivenza per il tempo che intercorre tra il prelievo e la semina.

Se il campione è costituito da materiale quali: feci, urine, sangue, liquor, escreato, liquidi pleurici, broncoaspirati...., i virus possono sopravvivere per un max di 2 ore.

Al momento della semina il campione va risospeso e trattato con antibiotici o filtrato.

Se i campioni sono prelevati mediante tamponi (che possono seccarsi durante il tempo di trasporto), devono essere immersi in terreni di trasporto, chiamati VTM (virus transport medium).

E' importante che il volume del VTM non ecceda i $2 \mathrm{~mL}$ per non diluire eccessivamente il virus in caso di bassa carica .

Il terreno più comune per il trasporto e la coltura cellulare in vitro è il MEM (Minimum Essential Medium), con l'aggiunta del $10 \%$ di siero bovino fetale, ottimo conservante cellulare, ed una miscellanea di antibiotici a largo spettro, comprendente anche un antifungino (streptomicina 10 $\mathrm{mg} / \mathrm{mL}$, penicillina $10.000 \mathrm{U} / \mathrm{mL}$, anfotericinaB $25 \mu \mathrm{g} / \mathrm{mL}$ ).

La miscela antibiotica viene fatta agire per $1 \mathrm{~h}$, prima della semina, al fine di bloccare ogni crescita batterica che possa interferire con l'isolamento virale.

I campioni vanno seminati entro le due ore dal prelievo (si sconsigliano i tamponi di cotone e alginato di calcio, essendo provata la loro interferenza con l'isolamento virale).

Analogo discorso viene fatto per la ricerca della Chlamydia Trachomatis, batterio, non virus, ma anch'esso parassita endocellulare obbligato.

Il terreno di trasporto utilizzato è il 2 SP che ha una alta percentuale di saccarosio, $56 \mathrm{gr} / \mathrm{L}$, e di siero $(100 \mathrm{~mL} / \mathrm{L})$, ottimo crioconservante.

I terreni di trasporto reperibili in commercio presentano caratteristiche analoghe.

\section{Preanalitica in BIOLOGIA MOLECOLARE}

La ricerca degli acidi nucleici dei microrganismi può essere eseguita su tutti i campioni diagnostici. Le endonucleasi sono i peggiori nemici della preanalitica in biologia molecolare.

Le endonucleasi, DNAsi e RNAsi in particolare sono delle proteine prodotte dalle cellula umane e batteriche al fine di difendere il proprio patrimo-

Tabella 10. Riassunto indicazioni per i contenitori , tempo di trasporto e modalità di conservazione in rapporto agli esami.

\begin{tabular}{|c|c|c|c|c|}
\hline ESAME & $\begin{array}{c}\text { TIPO DI } \\
\text { CONTENITORE }\end{array}$ & $\begin{array}{l}\text { TEMPO DI } \\
\text { TRASPORTO }\end{array}$ & $\begin{array}{l}\text { MODI E TEMPI DI } \\
\text { CONSERVAZIONE }\end{array}$ & NOTE \\
\hline $\begin{array}{l}\text { RICERCA Ab } \\
\text { TRAMITE } \\
\text { FISS AZIONE DEL } \\
\text { COMPLEMENTO }\end{array}$ & $\begin{array}{l}\text { STERILE CON } \\
\text { GRANULI DI } \\
\text { POLISTIRENE }\end{array}$ & $\begin{array}{l}\text { Sierare quanto } \\
\text { prima }\end{array}$ & $\begin{array}{l}2-8^{\circ} \mathrm{C} \text { per pochi } \\
\text { giorni } \\
-20^{\circ} \mathrm{C} \text { per molti } \\
\text { mesi }\end{array}$ & \\
\hline $\begin{array}{l}\text { RIC ANTICORPI } \\
\text { EPITOPI VIRALI } \\
\text { AUTOANTICORPI E } \\
\text { ALLERGOMETRIA }\end{array}$ & $\begin{array}{c}\text { PROVETTA STERILE } \\
\text { CON EDTA }\end{array}$ & $\begin{array}{l}\text { Sierare quanto } \\
\text { prima }\end{array}$ & $\begin{array}{l}2-8^{\circ} \mathrm{C} \text { per pochi } \\
\text { giorni } \\
-20^{\circ} \mathrm{C} \text { per molti } \\
\text { mesi }\end{array}$ & \\
\hline $\begin{array}{c}\mathrm{Ag} \\
\text { CELLULARI }\end{array}$ & $\begin{array}{c}\text { PROVETTA STERILE } \\
\text { CON EDTA }\end{array}$ & & $\begin{array}{l}\text { SEPARARE } \\
\text { entro } 24 \text { ore }\end{array}$ & \\
\hline $\begin{array}{l}\text { VIROLOGIA } \\
\text { DIRETTA }\end{array}$ & $\begin{array}{c}\text { VTM e 2SP } \\
\text { INTERI : FECI- } \\
\text { URINE - LIQUOR - } \\
\text { PLASMA }\end{array}$ & $\begin{array}{l}\text { ENTRO } \\
1 \mathrm{~h} 30 ”\end{array}$ & $\begin{array}{c}\text { SEMINARE } \\
\text { QUANTO P RIMA IN } \\
\text { COLTURE } \\
\text { CELLULARI }\end{array}$ & $\begin{array}{l}\text { CONSERVAZIONE } \\
\text { ESTREMAMENTE } \\
\text { DELICATA }\end{array}$ \\
\hline $\begin{array}{l}\text { BIOLOGIA } \\
\text { MOLECOLARE }\end{array}$ & $\begin{array}{l}\text { PLASMA- 2SP- } \\
\text { ZECCHE - LIQUOR } \\
\text { - SALIVA - URINE } \\
\text { BIOPSIE-HPV }\end{array}$ & $\begin{array}{l}\text { ENTRO } 1 \text { h } 30 " \\
\text { (o prelievo } \\
\text { congelato) }\end{array}$ & $\begin{array}{c}\text { SIERARE ENTRO } \\
6 \text { ORE E } \\
\text { CONGELARE A } \\
-70^{\circ} \mathrm{c}\end{array}$ & $\begin{array}{l}\text { SOLO } 2 \\
\text { CICLI DI } \\
\text { CONG E } \\
\text { SCONG }\end{array}$ \\
\hline
\end{tabular}


nio genetico dall'aggressione di sequenze genetiche estranee.

Per costituzione il DNA è più resistente dell'RNA, in più le RNAsi risultano essere più resistenti delle DNAsi, perché non necessitano di ioni metallo per essere attivate e inoltre si adsorbono a vetro e plastica e permangono attive anche dopo un ciclo di sterilizzazione.

Tali proteine avvolgono l'acido nucleico formando dei legami forti che spezzano casualmente o secondo sequenze palindromiche precise l'RNA o il DNA interessato.

Se tali palindromi sono presenti anche nella stessa cellula che produce le endonucleasi di difesa, essi sono protetti da gruppi chimici nelle rispettive basi di legame in modo tale che le armi prodotte dalla cellula per difendersi non ricadano su se stessa.

Sterilizzare le endonuclesi non serve a nulla se si supera la concentrazione di $10 \mathrm{ng} / \mathrm{mL}$, poiché quando si raffreddano gli oggetti sterilizzati, riprendono la forma terziaria originaria e una grossa percentuale di esse torna ad essere attiva. Inoltre se sono presenti dei batteri, dopo la sterilizzazione ,questi, in seguito a lisi , possono liberare le endonucleasi che contengono per la loro difesa, e dopo il raffreddamento riprendono in parte la loro attività endonucleasica.

Quindi l'unica soluzione per ovviare a questi inconvenienti è di operare come segue:

a)operare sempre con i guanti (le endonucleasi sono presenti a livello dell'epidermide)

b) usare materiali monouso RNAsi e DNAsi "free"

c) separare nel più breve tempo possibile il siero o plasma dalla parte corpuscolata del sangue

d) congelare subito il campione, se non viene analizzato subito

Le RNAsi, tuttavia, sono estremamente attive in presenza di RNA libero (lo inattivano in 5"-15"), mentre l'RNA nelle particelle virali integre viene protetto e resiste più a lungo.

La Tabella 10 riassume tutte le indicazioni date.

\section{BIBLIOGRAFIA}

1. Clinical Microbiology Procedures Handbook 1992 Henry D. Isenberg Vol 1 Specimen collection and Transport

2. Clinical Microbiology Procedures Handbook 1992 Henry D. Isenberg Vol 2 Quality Control 13.2.13

3. K.Van Hom, Clara Toth and JaneWegienek- Viability of aerobic microrganisms in four swab systems - ASM 98 th General Meeting. Atlanta, Georgia, May 1998

4. Lauer BA, Masters HB - Toxic effect of calcium alginate on Neisseria gonorrhoeae - J. Clin. Microbiol. 1988 Jan; 26(1): 54-6
5. Mandler F., Sfondrini D. - Evalution of survival of bacteria on dry swabs and transport systemAnn.Sclavo 1977 Jul-Aug; 19(4); 537-45

6. Jack L.Perry - Assessment of swab Transport systems for Aerobic and Anaerobic Organism RecoveryJ.Clin.Microbiol.1997 May, p.1269-1271

7. J.M.Campos, L.Ruthman and M.Tshimanga - Survival of Fastidious Bacteria on Specimen Collection Swabs Stored at Room Temperature - ASM 2000 General Meeting, Los Angeles California, 105/C. Specimen Collection, Transportation, and Processing. May $23^{\text {rd }}$, 2000

8. Jack L.Perry - Effects of Temperature on Fastidious Organism Viability during Swab Tansport- ASM 101 ${ }^{\text {st }}$ General Meeting, Orlando, Florida; May 2001. Poster Session 29/C. Specimen Collection, Transportation, and Processing.

9. NCCLS - Document M40-P Quality Control of Microbiological Transport Systems; Proposed Standard (ISBN 1 -56238-465-1) USA 2002

10. Arbique J, Campbell S, MacFarlane M, and Davidson RJ - Comparison of Methodologies Described in NCCLS Document M40-P Quality Control of Microbiological Transport Devices - ASM $103^{\text {rd }}$ General Meeting, Washington, D.C. May 2003

11. J.1.Perry and J.S. Matthews - Compliance of Two Popular Swab Transport Systems with Performance Standards Detailed by the new NCCLS Proposed Standard, M40-P - ASM 103 rd General Meeting, Washington, D.C. May 2003

12. Center for Disease Control and Prevention Recommendations for the Collection of Laboratory Specimens associates with outbreaks of gastroenterics. MMWR 1990,39

13. AMCLI-CoSP-Parassitosi intestinali autoctone e di importazione- proposta linee guida e protocolli operativi

14. AMCLI - CoSMic - Proposta di linee guida per la diagnosi microbiologica dei micobatteri - Microbiologia Medica, vol.14, numero 4,1999

15. F.Barberi, D. Crotti, D. Galli, A. Raglio - Manuale illustrato di diagnostica parassitologia - BIO-DEV 